\title{
BEQUESTS, INHERITANCES AND FAMILY TRADITIONS
}

\author{
Donald Cox and Oded Stark* \\ CRR WP 2005-09 \\ Released: August 2005 \\ Draft Submitted: March 2005
Center for Retirement Research at Boston College 550 Fulton Hall
140 Commonwealth Ave. Chestnut Hill, MA 02467
Tel: 617-552-1762 Fax: 617-552-0191
http://www.bc.edu/crr

*Donald Cox is a Professor of Economics at Boston College. Oded Stark is a Professor of Economics at the University of Bonn. The research reported herein was performed pursuant to a grant from the U.S. Social Security Administration (SSA) to the Center for Retirement Research at Boston College (CRR). The findings and conclusions are solely those of the authors and do not represent the views of SSA, any agency of the Federal Government, or Boston College.

(C) 2005, by Donald Cox and Oded Stark. All rights reserved. Short sections of text, not to exceed two paragraphs, may be quoted without explicit permission provided that full credit, including (C) notice, is given to the source. 


\section{About the Center for Retirement Research}

The Center for Retirement Research at Boston College, part of a consortium that includes a parallel centers at the University of Michigan and the National Bureau of Economic Research, was established in 1998 through a grant from the Social Security Administration. The goals of the Center are to promote research on retirement issues, to transmit new findings to the policy community and the public, to help train new scholars, and to broaden access to valuable data sources. Through these initiatives, the Center hopes to forge a strong link between the academic and policy communities around an issue of critical importance to the nation's future.

\section{Center for Retirement Research at Boston College \\ 550 Fulton Hall \\ 140 Commonwealth Ave. \\ Chestnut Hill, MA 02467 \\ phone: 617-552-1762 fax: 617-552-0191 \\ e-mail: crr@bc.edu \\ http://www.bc.edu/crr}

\section{Affiliated Institutions:}

American Enterprise Institute

The Brookings Institution

Center for Strategic and International Studies

Massachusetts Institute of Technology

Syracuse University

Urban Institute 


\begin{abstract}
Do "family traditions" influence bequest behavior? If an individual receives an inheritance from his parents, is he more likely to give a bequest to his children, even after controlling for the boost in wealth conferred by the inheritance? Family traditions are pertinent to a host of issues connected with intergenerational transfers: Ricardian equivalence and crowding out, the role of bequests in wealth accumulation, and the responsiveness of bequests to tax changes. Traditions also matter for issues related to behavioral economics, such as mental accounts, social learning, and the intergenerational transmission of values. Partially due to the paucity of data, few studies to date have analyzed bequests in conjunction with inheritances. We draw upon the U.S. Health and Retirement Survey, one of the few data sets with comprehensive information on both bequests and inheritances. We find that receipt of inheritances and intended bequests are positively and significantly related (both behaviorally and statistically) even after controlling for a host of household characteristics, most importantly household net worth. Discerning how to label this partial correlation is a daunting task. We provide a precise definition of "family traditions" and we show how they differ from other channels of influence. Our explanation of the nuances of traditions hinges on measuring the flexibility of bequest plans when wealth or other circumstances change. (For instance, will a wealth shortfall have a smaller impact on an inheritor who may be attempting to carry on a family tradition?) We find evidence in support of the idea that the propensity to bequeath out of wealth differs depending upon whether current wealth is large or small relative to inheritances received. We conclude that economists interested in
\end{abstract}


intergenerational transfers should pay attention to the role of family traditions in bequest behavior.

Keywords: Inheritances; Family traditions; Bequests; Wealth JEL classification: A14; D10; I30; J13; J14; J26 


\section{Introduction}

We seek answers to the following questions. Consider an individual who receives an inheritance from his parents. Is that individual more likely to give a bequest to his children, even after controlling for the boost in wealth conferred by the inheritance? Does the receipt of an inheritance impinge on the flexibility of bequest plans when wealth or other circumstances change? For example, will a wealth shortfall have a smaller effect on the bequest plans of a recipient of an inheritance who is attempting to "carry on a family tradition," than on the bequest plans of an otherwise similar individual whose family has no tradition of inheritances and bequests? We address these and related questions analytically and, using data from the U.S. Health and Retirement Survey (HRS), empirically. We also study the implications of family traditions for the responsiveness of family transfers to policy changes.

We argue that a "family traditions" approach linking bequests and inheritances is important for several reasons. First, family traditions are pertinent to the problems of Ricardian equivalence and crowding out. Altruistic households with operative bequest motives might nonetheless be quite insensitive to government redistribution of income when family traditions matter. Second, family traditions are relevant for the relationship between bequests and wealth accumulation. An economy inhabited by households who inherit and are loath to break with the tradition of bequeathing will accumulate more bequest-related wealth than an economy without such a tradition. Third, traditions affect the extent to which a tax policy can alter bequest behavior. Like a smoker habituated to nicotine, a bequeathing parent with a tradition to uphold might be less sensitive to a specific tax policy than his less tradition-bound counterpart.

We contend that family traditions might matter for reasons other than the ones (like those cited above) that typically attract the lion's share of attention in the intergenerational transfers literature. Our family traditions approach, for example, can rationalize what would otherwise appear to be the existence of arbitrary mental accounts 
wherein the propensity to bequeath out of inherited wealth exceeds the propensity to bequeath out of non-inherited wealth.

Our research is related to an emerging groundswell within economics that seeks to understand where preferences come from. In particular, we are interested in the role of social learning and the intergenerational transmission of preferences in bequest behavior. This is the most important motivation for our study. The endogenous formation of preferences is a frontier issue in economics. But it poses challenging problems, since it is not easy to distinguish between the effects of social learning or parental enculturation and other - perhaps distinct and spurious - forces that might generate a positive intergenerational correlation in bequest behavior.

Despite the potential importance of family traditions in bequest behavior, there is very little literature in this area. The main reason could well be data limitations; most data sets with information on intergenerational transfers contain detailed information either on inheritances received or on bequests given, but not on both. We propose to fill this gap by using the Health and Retirement Survey (HRS), a large, detailed panel study of households designed to study the economic life of households from midlife to death. The HRS contains information that is ideal for tackling the role of family traditions in bequest behavior.

Our findings to date are concerned with both evidence and logic related to family traditions. On the evidence front: we find a large, significant, and robust effect of inheritances on intended bequests. The correlation between bequests and inheritances persists after controlling for a host of covariates commonly implicated in bequest behavior. On the logic front: what exactly is a tradition? We provide a framework for understanding the logic of family traditions, and examine its predictions for the wealth effects of bequests. Our model predicts differing propensities to bequeath out of wealth, depending on how much wealth the household has in relation to the inheritances that it has received. We find evidence consistent with this framework. Households whose stock of bequeathable wealth falls short of their inheritance appear to have a much higher 
propensity to bequeath out of wealth than households whose wealth well exceeds their inheritance.

\section{Bequests, inheritances, and traditions in the grand scheme of things}

Our "traditions" approach is pertinent to each of the three leading issues in the literature on intergenerational transfers: the "crowding out" issue raised in the seminal papers of Becker (1974) and Barro (1974); the role of intergenerational transfers in wealth accumulation, first identified in Kotlikoff and Summers' (1981) classic paper; and the influence of tax policy on intergenerational transfers. Later in this section we argue that our approach is also pertinent to issues in behavioral economics, in particular the emerging literature on the formation of preferences, as well as the older but related literature outside of economics that is concerned with the evolution of culture.

\section{Crowding Out}

Much of the interest in intergenerational transfers in the past three decades or so has been fueled by the specter of "crowding out" - the idea that the impact of public income redistribution can be neutralized by offsetting adjustments in private transfers. Barro (1974) emphasized the intertemporal aspects of crowding out: debt-financed fiscal policy need not raise the consumption of current generations, but could instead simply prompt increased bequests, so as to leave the intergenerational distribution of consumption unchanged. Becker (1974) emphasized the cross-sectional aspects of crowding out: a boost in aid to the poor need not increase the consumption of the poor, because the aid could prompt reductions in private transfers to the poor, leaving the distribution of consumption unchanged.

It is quite straightforward to illustrate how family traditions can weaken (or even cancel out) these neutrality results. Consider a simple variant of the Becker's (1974) model, in which an altruistic parent cares about his consumption and about his child's felicity ( $c_{p}$ and $V\left(c_{k}\right)$, respectively), as well as about the size of the bequest, $B$, that the child will receive relative to the value of the inheritance, $I$, that the parent received from 
his own parent. (For simplicity's sake and in order to allow us to concentrate on essentials, we assume that the child has no child of his own; there are merely two generations.)

The parent's utility function is

$$
U=U\left(c_{p}, V\left(c_{k}\right), f(B-I)\right) .
$$

Assume that (1) is quasi-concave and increasing in each of its arguments. The budget constraints of the parent and of the child are, respectively,

$$
c_{p}=Y_{p}+I-B
$$

and

$$
c_{k}=Y_{k}+B
$$

where $Y_{i},(i=p, k)$ denotes the non-transfer income (human wealth, say) of the parent, $p$, and of the child, $k$. With this simple framework, it is easy to show that crowding out is attenuated in the presence of family traditions: the so-called "transfer derivative," which measures the effect on bequests of a one dollar increase in $Y_{p}$ matched by a one dollar reduction in $Y_{k}, \partial B / \partial Y_{p}-\partial B / \partial Y_{k}$, is less than unity. Indeed for certain parameterizations of (1), the transfer derivative (and therefore crowding out) can be zero. ${ }^{1}$

\section{Adjacent Complementarity}

Family traditions imply a dynastic version of the "adjacent complementarity" concept emphasized in the habit models of Becker and Murphy (1988) and Becker (1992). Leaving aside the obvious income effect of an increase in $I$ on $B$, equations (1), (2) and (3) imply that with total parental income, $Y_{p}+I$, held constant, $\partial B / \partial I>0$. The parent inherits more than just funds; the parent inherits a habit of giving, since the marginal

\footnotetext{
${ }^{1}$ For instance, if (1) is given by $U=\ln \left(c_{p}\right)+\alpha \ln \left(c_{k}\right)+\phi \ln (B-I)$, where $\alpha$ is the weight that the parent attaches to the felicity his child gains from consumption, the transfer derivative approaches zero as the utility-maximizing value of $B$ approaches $I$. Equation (1) is a variation on a theme introduced by Andreoni (1989).
} 
utility of bequests rises with $I$. Such a complementarity implies that giving begets giving, generating heterogeneity across dynasties in the propensity to bequeath lifetime resources.

\section{Mental Accounts and Anomalies}

Behavioral economists, most notably Thaler (1990), alluded to the idea of "mental accounts," whereby people pay attention to individual sources of income or wealth, in spite of the fungibility of money across sources. (An individual might, for example, place bigger bets at the blackjack table after winning a large pot, not because his budget constraint has shifted out but because he says to himself that he is playing with "their money," which is somehow different from "his own money," inspite of the obvious truth that the money is indeed, at least for now, his own money!) Thaler's description of mental accounting can be expressed in the following syllogism: (a) if money is fungible, and (b) if people have different marginal propensities to consume (MPC) out of income depending on its source, then (c) there is an anomaly afoot. Thaler's approach to resolving these anomalies involves stepping outside the rational, homo economicus characterization of persons so as to emphasize some foible or quirk such as the inability to control one's consumption or the failure to understand the workings of budget constraints as taught in the introductory economics course Econ 101.

Our "family traditions" approach characterized by (1) features differing marginal propensities to bequeath out of inherited versus non-inherited income: $\partial B / \partial I>\partial B / \partial Y_{p}$, despite the fact that $I$ and $Y_{p}$ are obviously fungible. Does this constitute an anomaly? Although this question has partly to do with semantics, we submit that the answer is "no." We have tweaked the standard Becker-Barro model of parental altruism in an exceedingly minor way by just introducing the possibility that the parent cares about upholding the tradition. Why and how the term $f(B-I)$ entered the parent's utility function in the first place are important issues that merit further study. (Note that we have not strayed too far from the framework of homo economicus in order to rationalize the presence of the $f(B-I)$ term. $)$ 


\section{Biology versus Culture}

One way of characterizing the term $f(B-I)$ versus the term $V\left(c_{k}\right)$ in (1) is that the first term represents "cultural" forces, while the second term represents "biological" forces. More conventional treatments of parental giving, starting with Becker's (1974) approach, tend to focus only upon the latter, which might most aptly be characterized as a framework for analyzing parental investments in very young children. But there may be a need to distinguish between parental investments in very young children and in older children. Becker's approach has its antecedents in the work of evolutionary biologists, notably Hamilton (1964), who formulated a biological rationale for kin-based altruism. But Hamilton's approach, in which a parent helps to propagate his genetic code by helping his children to survive and reproduce, could well be more appropriate for characterizing the care of very young children than of adult children. Becker did not make much of a distinction between young children and adult children, but perhaps he should have. When a thirsty one-year-old child cries, the parent prepares a bottle without thinking. But what will the parent's reaction be when, at the age of 33, the child appears on the parent's doorstep broke, seemingly a loser, and asks to move back in? The biological machinery honed during the Pleistocene that hard-wired the preferences to care for an infant could well be irrelevant for guiding decisions to care for a needy adult child. (How many Pleistocene parents even lived long enough to interact with their adult children?)

If biology is not the dominant impetus for guiding preferences for caring for a 33year-old son, what is? An alternative force is that of culture. Genuinely perplexed about the "right" approach to dealing with a needy 33-year-old son, a parent might ask himself what others (a colleague, a neighbor, his own father) would do if faced with a similar situation. In other words, preferences about how to treat adult children might well be guided more by social learning than by biological hard-wiring. Hence, the potential importance of traditions in guiding bequest decisions; after all, most bequests do go to independent adults, not to dependent or helpless children. 
Note too that this line of argument is not about budget constraints: the mewling infant and the wheedling 33-year-old are both "broke," in a sense. It is just that their cries may well resonate in distinct modules of the parent's mind. It might not be so much Hamilton's Rule that guides bequest behavior but, rather, concerns about "doing the right thing," which are learned from one's forebears.

\section{Taxes and Other Economic Forces}

Despite the somewhat chaotic state of the empirical literature on private transfer behavior, there is an emerging consensus that bequests and gifts are not as sensitive to incomes and prices as mainstream models of private transfer behavior predict. For example, the response of bequests and gifts to the recipient's income is nowhere near the magnitude implied by the standard altruistic model. Furthermore, individuals do not appear to take full account of tax incentives when deciding the mode and amount of their transfers to children and relatives (see, for example, Poterba (2001), McGarry (2001)). ${ }^{2}$

Our family traditions approach explains the apparent inelasticity of bequests with respect to taxes. The argument parallels the one that we have delineated with respect to crowding out. Imagine that bequests are taxed at the rate $\tau$, and, for the sake of illustration, suppose that $f(\cdot)$ in (1) is now $f((1-\tau) B-I)$, so that parents care about their after-tax bequests. It is easy to see that the absolute value of $\partial B / \partial \tau$ falls when the marginal utility of traditions looms large (that is, when the utility maximizing value of $(1-\tau) B$ is close to $I)$. For instance, if $f$ were a $\log$ function, $\partial B / \partial \tau=0$ when $(1-\tau) B=I{ }^{3}$ In this case, tax considerations take a back seat in view of the desire to uphold the family tradition.

\footnotetext{
${ }^{2}$ These authors emphasize the choice of transferring via bequests versus inter-vivos gifts, and find that households often forego substantial sums of money by failing to choose the giving patterns that would minimize their tax liability.

${ }^{3}$ More recently, Bernheim, Lemke and Sholz (2004) have entered the tax-effects debate by emphasizing that households may need to balance tax minimization against other exigencies such as uncertainty about health care needs or the desire to use bequests to exert leverage over child behavior. Our line of reasoning is in the same vein, but the hypothesized concerns of parents about family traditions represents a completely different rationale for the impact of taxes on private transfers.
} 


\section{Policy Impact in the Short and Long Run}

Once traditions are taken into account, there is an important distinction between short and long run responses to prices, incomes, or policy changes. ${ }^{4}$ Consider the recent passage in the U.S. House of Representatives of a bill to repeal the inheritance taxes by 2010 . Advocates of the bill argue that estate taxes have a dampening effect on the propensity to bequeath family businesses and other assets to children, and that repealing the tax would stimulate these transfers and induce the kind of behavior that facilitates such transfers. But if traditions play an important role in private transfer behavior, the short-run impact on behavior of the repeal of the estate tax could be inconsequential. On the other hand, as initial small changes in giving beget subsequent changes in giving by later generations, initial small responses snowball into larger ones down the road. Our "traditions" approach implies that the initial response to a change in estate tax policy might be a poor predictor of the eventual policy effect in the long-run steady state.

\section{Traditions, Bequests and Wealth Accumulation}

If part of the reason why individuals save is to amass an estate, and if individuals are concerned that their bequests do not pale in comparison to their inheritance then family traditions will affect wealth accumulation. To illustrate, consider two countries (or cultures) consisting of dynastic parent-child dyads. Country "A" has a tradition that a parent can leave to his child whatever he wants, as long as he does not leave less than he himself received from his own parent. Country "B" has no such tradition. Wealth accumulation in "A" will exceed wealth accumulation in "B," because "A"s tradition places a floor beneath which bequest-related wealth accumulation cannot fall.

\section{Traditions and Stratification in Economic Resources}

Until fairly recently, it was thought that U.S. dynastic wealth stratification was rather weak. For example, Becker and Tomes' (1986) review of early (mostly cross-sectional) evidence intimated that the catchphrase "shirtsleeves to shirtsleeves in three generations" might not be a bad characterization of the intergenerational regression to the mean in earnings. Subsequent research using panel data, starting with Behrman and Taubman

\footnotetext{
${ }^{4}$ This point parallels the one made by Becker and Murphy (1988) in the context of habits and addictions.
} 
(1990), focused on permanent incomes and produced higher intergenerational correlations, suggesting that the Becker-Tomes description of economic stratification was premature.

More recently, economists have sought to move beyond the description of intergenerational correlations in income or wealth, focusing instead on variables that are more closely tied to behavior rather than to budget constraints. Recent studies, for example, attempt to measure intergenerational correlations in portfolio composition, savings, and consumption behavior (see, for example, Chiteji and Stafford (1999), Hurst and Charles (2003) and Waldkirch, Ng and Cox (2004)) and charitable contributions (Wilhelm, Brown, Rooney and Steinberg (2004)). Our inquiry fits into this vein of research, extending the behavioral domain to include intergenerational transfers.

\section{What do we already know about the inheritance-bequest relationship?}

Despite the potential importance of family traditions for bequest behavior, we currently know little about them, largely because of data limitations. Most previously used data sets contain information either about bequests or about inheritances, but only rarely about both. Further, prior to the work on the "demonstration effect" (Cox and Stark (1996) $)^{5}$, the modeling of intergenerational transfer behavior was limited to the analysis of only two generations. Partly in response to our call to researchers to expand the domain of inquiry from two generations to three, a growing cadre of economists have focused on household survey data sets capable of providing such extended information.

For instance, there is growing research based upon the 1992 French CNAV ("Caisse Nationale d'Assurance Vieillesse") survey and the French INSEE 1992 wealth survey, which has been analyzed by several researchers, most prominently Luc Arrondel, Andre Masson, Anne Leferriere, Francois-Charles Wolff, and Mohamed Jellal. For example, Arrondel, Masson and Pestieau (1997) find that intergenerational transfer patterns tend to be correlated from one generation to another. For instance, receiving an

\footnotetext{
${ }^{5}$ See also Cox and Stark (2005).
} 
inheritance through a will increases the probability that the recipient will likewise write a will. Arrondel and Masson (2001) report on a variety of complex constellations of empirical transfer patterns that occur in three generations. More recently, Jellal and Wolff (2002) have used the 1992 CNAV to investigate how one generation's inherited tastes in consumption preferences and in the propensity for transfers impact those of the next generation.

Most of this work is in its early stages, and much of it seeks to provide a taxonomy of the complex interrelationships that spring from models containing three or more generations. Several papers have made initial attempts to explore the logic of intergenerational influences, though none has proposed a convincing framework for distinguishing, say, "traditional" behavior from other channels of influence such as, for example, heterogeneity in tastes across family dynasties.

Essentially, we seek to advance our understanding of bequests and inheritances in two spheres: that of logic, and that of evidence. Concerning logic: we construct a model of traditional behavior that can potentially distinguish traditions from other forms of intergenerational influence, and that yields predicted changes in bequests as responses to variations in household wealth. Concerning evidence: we draw upon the HRS which, for several reasons, is far superior to other comparable data sets. The HRS chronicles in great detail the economic and family life of respondents from the middle to the end of their life-cycle. It contains both retrospective questions about private transfers received and prospective questions about intentions to make private transfers. The HRS employs stateof-the-art methods to measure household wealth, a variable which has been found to be perennially difficult to calculate, yet plays a crucial role in our analysis of the interplay between inheritances and bequests.

Further, the HRS is a panel. Our empirical work uses more than a decade's worth of information in 6 bi-annual waves spanning 1992 to 2002. Fortuitously, this period includes a rise and abrupt fall in the stock market, changes which have the potential to generate (at least for the select sample of stockholders whose portfolios were somewhat 
technology-heavy) credibly exogenous variation in wealth. In addition to the detailed modules on household balance sheets, labor market activity, family life, and private transfers, which are all pertinent to our empirical work, the HRS also contains a unique set of experimental modules used for random subsets of respondents. Some of these modules contain information directly relevant to the motivation for private transfers, and a recent study (Cox and Soldo (2004)) shows that by providing direct information on nuances in the motivation for private transfers, these "point-blank" questions can be useful complements to a more standard empirical work.

Before proceeding to the empirical work, however, we present a detailed analysis of the logic of family traditions.

\section{The logic of family traditions}

\subsection{The approach}

How might family traditions affect bequest behavior? To aid our thinking and to guide our empirical inquiry, we investigate the relationship between family traditions and bequests drawing on a simple model. A key finding of the model is that, all else being equal, having a larger fraction of wealth originating in inherited wealth increases the propensity to bequeath wealth. Results pertaining to the effect of wealth itself on bequests are less clear-cut. We show that traditions might either magnify or attenuate the effects of changes in wealth on intended bequests, and we provide illustrative examples of these alternative outcomes. Our conclusion is that the impact of family traditions on bequests cannot be ascertained by logical reasoning alone; an empirical inquiry is inescapable.

A tradition is partly a habit, partly a norm, and partly a goal. It is habit-like in that the choices of yesteryear affect decisions today, and it is norm-like in that past choices made by people other than person $i$ help shape the environment in which $i$ 's choices are made. More than anything else, it is the potentially goal-like aspect of a family tradition that distinguishes it from its analytical cousins of habit and norm. 
To illustrate: if $i$ receives an inheritance of $\$ 100,000$ from his father, and if $i$ cares about a "family tradition" of giving (and not just about the act of giving), then $i$ 's marginal utility of making a bequest to his son will follow a distinct pattern depending on the relationship between the size of $i$ 's inheritance and the size of $i$ 's bequest. (We set aside the impact of the inheritance on i's budget constraint, important as it may be, in order to focus strictly on the utility function and thereby on the "psychology" of giving.) The marginal utility of a dollar bequeathed might start off relatively low but increase as it approaches the value of $i$ 's inheritance. Adding a little bit to an inconsequential bequest would do little good because it would still pale in comparison to $i$ 's own inheritance - not a very gratifying result for someone seeking to uphold a family tradition. But as the intended bequest begins to approach the size of $i$ 's inheritance, the marginal utility of additional dollars bequeathed would rise. The closer $i$ gets to the goal of doing for his child what $i$ 's parent did for $i$, the more gratifying it would be to increase $i$ 's intended bequest. In a way, the value of $i$ 's inheritance, $\$ 100,000$, is a benchmark, a focal point, a watershed. Accordingly, $i$ 's marginal utility of bequeathing would peak at about $\$ 100,000$ and thereafter begin to fall, since additional dollars bequeathed are just icing on the cake, once $i$ has succeeded in upholding the tradition.

What would this rising-then-falling trend in the marginal utility of bequests imply for observable relationships, such as the relationship between intended bequests and wealth? One implication is that the composition of wealth by source, rather than the magnitude of wealth, matters greatly. Another implication is that in some instances bequests might have an "all-or-nothing" quality to them. If $i$ 's bequeathable wealth were miniscule in relation to $i$ 's inheritance (say $\$ 5,000$ compared to $\$ 100,000$ ), $i$ might be inclined to abandon the idea of leaving any bequest at all. Suppose now that $i$ 's bequeathable wealth starts rising thereby rendering the perpetuation of tradition ever more feasible. A change in wealth could prompt a large discrete jump in planned bequests. The reason is that the wealth change brings within striking range the achievement of a distinct goal. 
In contrast, a non-inheritor has no "positive" tradition to uphold. Accordingly, the transition from no bequest to a positive bequest could occur smoothly as bequeathable wealth rises. If bequeathable wealth rises from nothing to something small, the intended bequest could rise likewise; the testator is unencumbered by concerns about perpetuating a tradition to bequeath a specific amount.

This goal-like aspect of family tradition is not the family traditions only attribute; as we have already pointed out, traditions are also habit-like and norm-like. Having received inheritance boosts the marginal utility of bequeathing for all values of the intended bequest, so a tradition affects not just the shape of the marginal utility of bequeathing but also its level. The entire marginal utility schedule of bequeathing is higher for someone who has inherited; the larger the inheritance, the bigger the upward shift. Inheritance is thus analogous to what in the habit formation literature is referred to as the habit stock - something that encapsulates the consumer's history of consumption of a habit good. This literature emphasizes the notion of adjacent complementarity: a positive relationship between the marginal utility of consumption and the habit stock. In our context, adjacent complementarity implies that having inherited adds to the gratification associated with any additional dollar bequeathed.

To see that family traditions are partly norm, is simple: they are norm-like because the habit stock originates not from $i$ 's own behavior but from the behavior of others. What $i$ inherits from his father is more than just wealth; $i$ inherits a tradition. The combined logic of habit-like and norm-like aspects of family traditions suggests that of two individuals with the same bequeathable wealth, the individual who inherited more will bequeath more.

\subsection{A detailed consideration}

Consider a single parent with a single child. The parent has bequeathable wealth $W$, which consists of an inheritance, $I$, in addition to non-inherited wealth, $Y$. How does the optimal bequest, $B$, that the parent will give to his child relate to $I$ ? Being a 
component of $W, I$ clearly affects the parent's budget constraint. The key to the effect of family tradition is a connection between bequests and inheritances not via the budget constraint, however, but via the utility function; we postulate that $I$ affects the psychology of giving. Let the parent's utility function be

$$
U=U(c, B, I)
$$

where $c$ represents the parent's consumption. Family traditions imply that:

The marginal utility of $B$ is at its highest when $B=I$ (goal orientedness),

The marginal utility of B increases with I (adjacent complementarity).

How would bequests respond to inherited wealth in the presence of a family tradition? Consider the diagram depicted in Figure 1, which illustrates how a utilitymaximizing consumer would divide his wealth between consumption and bequests. The length of the horizontal axis depicts total wealth, $W$, which is allocated between $c$ and $B$. $B$ is measured from left to right; $c$ is measured from right to left. Thus, every abscissa represents a specific division of wealth between consumption and bequests. The left vertical axis depicts the marginal utility of $B$; it is rising in $B$ up until the point where $B$ equals $I$ and is falling thereafter. The right vertical axis depicts the marginal utility of $c$; this marginal utility falls as $c$ rises. An intuitive way to read Figure 1 is to think of the marginal utility of consumption as the marginal cost of bequests. Equating the marginal benefit of bequeathing to its marginal cost determines the utility-maximizing split of wealth between $B$ and $c$, depicted as point $e$, which implies (in this example) that the optimal bequest exceeds the inheritance $I$. 


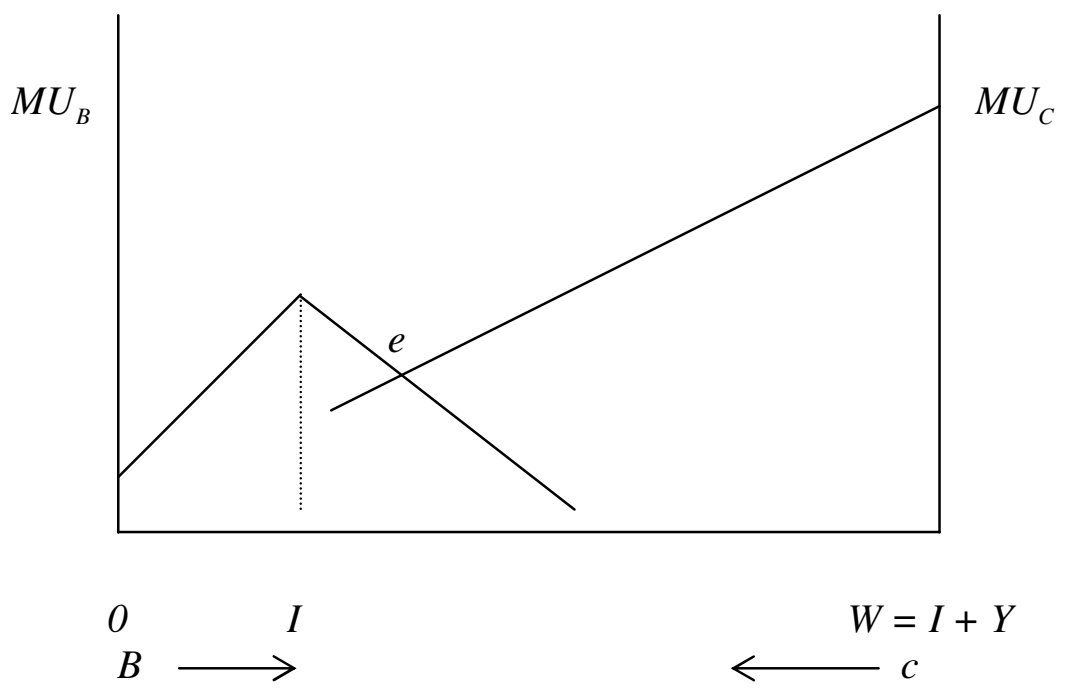

Figure 1. An illustration of an optimal bequest with family traditions

Another parent with the same inheritance $I$ but with less non-inherited wealth, say $Y_{0}$, could find it optimal to bequeath nothing (Figure 2). Graphically, a smaller $Y$ shrinks the base of the diagram, which could result in the marginal cost of bequest everywhere exceeding the marginal benefit. (Figures 1 and 2 are drawn for the case in which $U$ is separable in $c$ and $B$, a simplifying assumption that does not cause us to lose anything essential.)

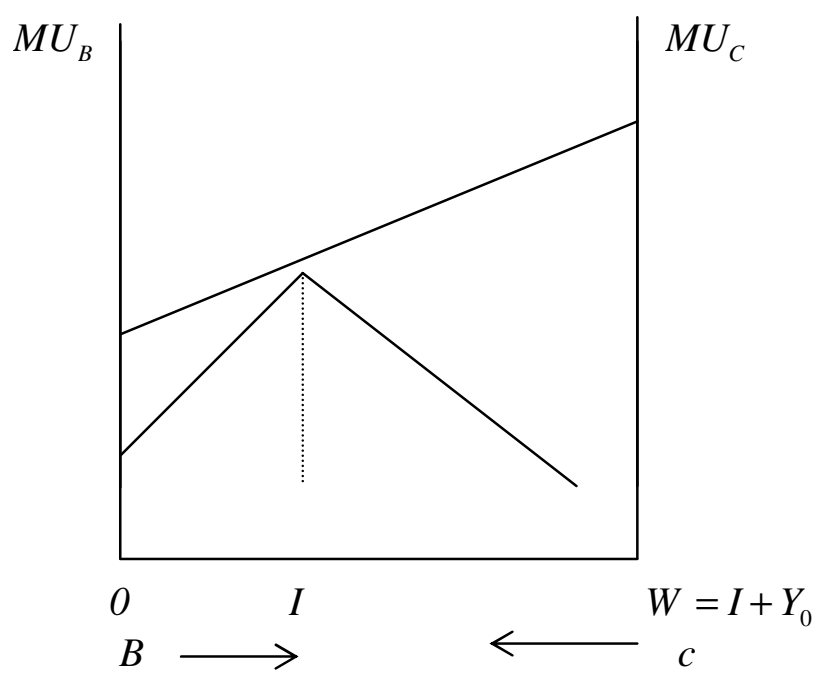

Figure 2. A no-bequest solution with a low value of $Y\left(Y=Y_{0}\right)$ 
From the no-bequest solution, a rise in non-inherited wealth can precipitate a discrete jump in bequests. An expansion of $Y$ (from $Y=Y_{0}$ ), entailing an expansion of the base of the figure implies that $M U_{B}$ evaluated at $(B=I)$ begins to exceed $M U_{c}$. Once $Y$ rises to the value $\hat{Y}$, as illustrated in Figure 3, the area $\Delta \mathrm{b}$ exceeds the area $\Delta \mathrm{a}$, and the equilibrium bequest jumps from 0 to the positive amount given by point $e^{\prime}$. It is worth emphasizing that this is a quantum jump in bequests, a switch from bequeathing nothing to bequeathing more than the inheritance $I$. (Clearly, $\tilde{e}$ cannot constitute a solution because to the right of $\tilde{e}$, the marginal benefit of bequeathing is higher than the marginal cost of bequeathing.)

Yet the jump in intended bequests depicted in Figure 3 need not occur; Figure 4 depicts what could happen if utility is more concave in consumption. The equilibrium is now depicted by $e$ ". Despite the tradition, intended bequests rise continuously with wealth but fail to reach the level of inheritance. Thus, a tradition is a necessary but not sufficient condition for discontinuous jumps in intended bequests.

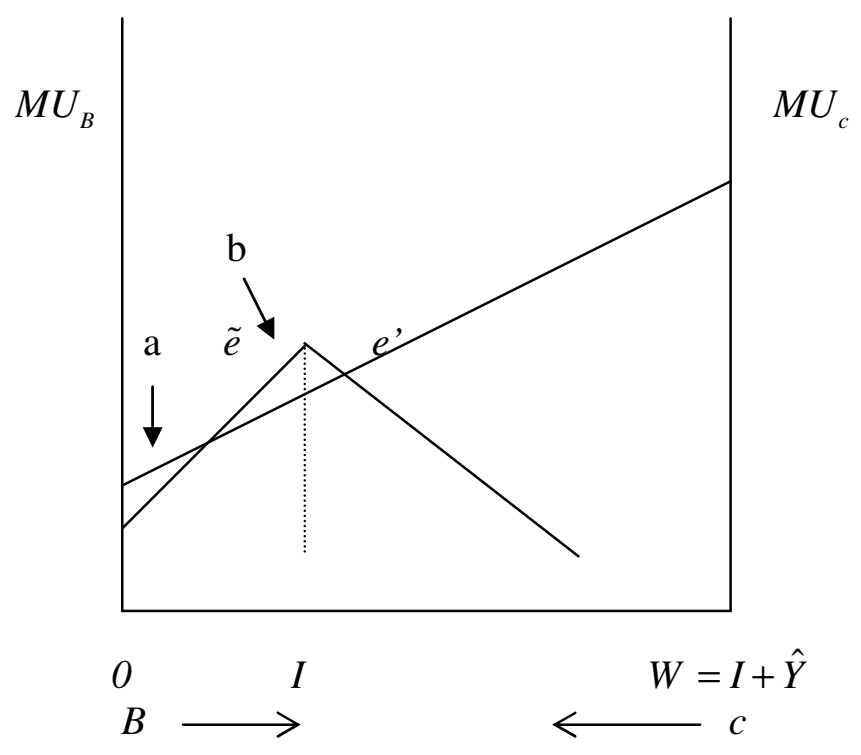

Figure 3. A quantum jump in intended bequests 


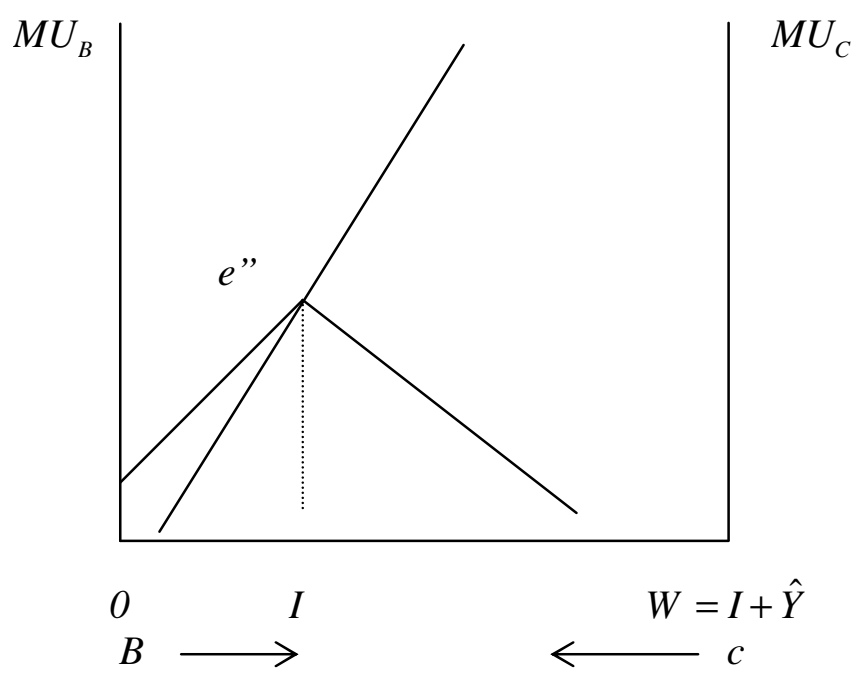

Figure 4. Traditions may not imply a quantum jump in intended bequests as wealth rises

Finally, imagine that family traditions entered the utility function in a slightly different way: the parent receives a discrete boost in utility from bequeathing an amount that is not less than that which he inherited. Call this discrete boost $\gamma$. The parent will bequeath exactly $I$ to his child if by choosing $B=I$ he will be able to secure the utility boost $\gamma$, that is, as long as

$$
\int_{W}^{W} M U_{C} d c \geq \gamma
$$

Define $\tilde{W}$ as the value of wealth for which (5) holds with equality. For $W \geq \tilde{W}$, intended bequests will be completely unresponsive to changes in $W$. But if $W$ falls below $\tilde{W}, B$ jumps to 0 , and in that sense the wealth-bequest relationship is similar to that depicted in Figure 1, where the existence of a tradition created conditions for small changes in wealth to generate large changes in (intended) bequests. 


\section{An empirical inquiry}

\subsection{The data}

We draw on data from the Health and Retirement Study (HRS). The HRS is an ongoing, longitudinal survey of households of pre-retirement age, first conducted in 1991 with interviews of 12,652 respondents from 7,702 U.S. households. The HRS has been conducted every two years. It contains special modules of questions on specific issues for sub-samples (usually around 10 percent) of respondents. The HRS provides extensive information on demographic characteristics, family structure, transfers, income, net worth, physical health, and other personal and household characteristics related to the decision to retire. Since the HRS is primarily concerned with pre-retirement behavior, it targets respondents who are in their fifties. What makes the HRS particularly useful for our purposes is that it contains information both about planned bequests and about past inheritances.

To focus exclusively on actual inheritances rather than on expected inheritances, we restrict our attention to respondents with no living parents. Further, since we are interested in those who might be motivated to bequeath to their children, we confine our sample to respondents with at least one descendent. (Details of our criteria for sample selection are provided in Appendix Table 1.). Our empirical analysis draws on responses provided to questions pertaining to intentions to bequeath; we do not know whether the intentions were matched by action. Yet for our purposes, it is the intentions that count, not realized behavior. The event of a bequest being made cannot reveal to us the reason for leaving the bequest. At most, we could establish a statistical relationship with the actual experience. The responses to intention questions enable us unveil a causal relationship. 


\subsection{On the relationship between inheritances and bequests}

Those HRS households who inherited are more likely to expect to bequeath, which itself is not all that surprising; having received renders it more affordable to give. However, it turns out that wealth is not the sole determinant of this propensity: a positive relationship between past inheritance and planned bequests holds up even after controlling for wealth. However, before considering the effect of wealth we depict some basic patterns in Table 1; we display the percentages of households who plan to leave a bequest by whether or not they inherited.

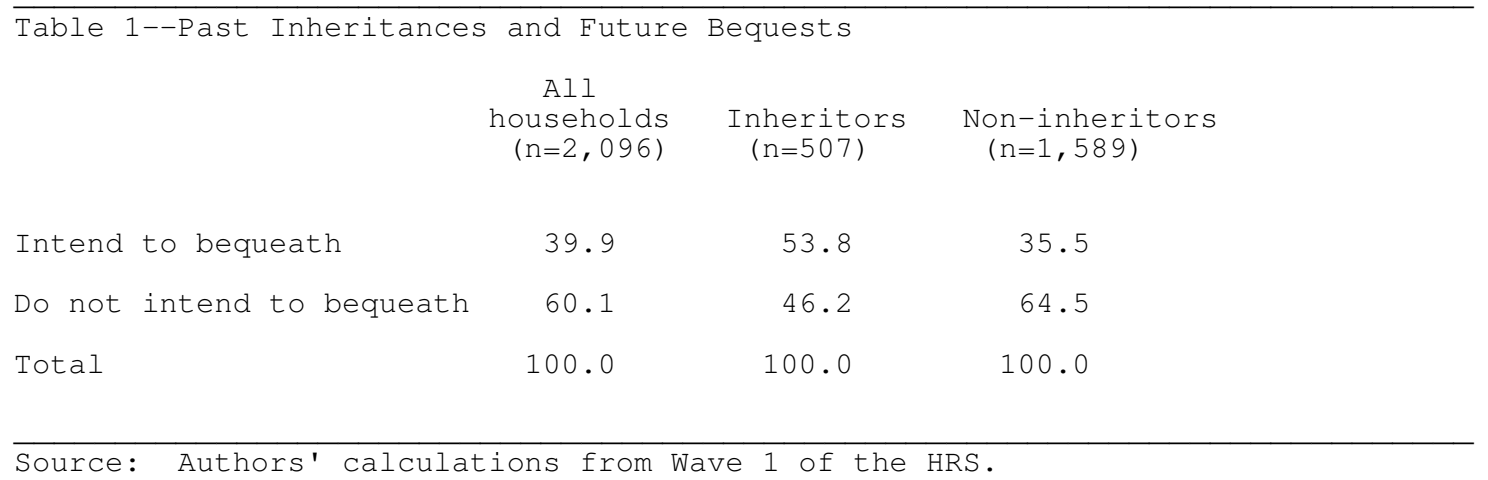

Nearly 40 percent of the respondents answered "yes" when asked "Do you [and your husband/wife/partner] expect to leave a sizeable inheritance to your heirs?" Among the sample of inheritors, however, a much larger fraction - 54 percent - answered yes when asked this question compared to the 36 percent who answered yes among noninheritors. ${ }^{6}$ Respondents chose from gradations of "yes" and "no," ranging from a definite "yes" to a definite "no." These refined responses are depicted in Figure 5, which reinforces Table 1; inheritors are more likely to plan to leave bequests.

\section{FIGURE 5 HERE}

\footnotetext{
${ }^{6}$ Inheritors are households whose respondents or spouses have ever received an inheritance, not assets in the form of a trust.
} 
Expecting to leave a bequest does not necessarily indicate a bequest motive in the sense of intending to leave a bequest. An individual might attach little value to leaving a bequest yet still expect to leave one merely because of a reasonable expectation of dying prior to consuming all his assets, thereby leaving an "accidental bequest" (Davies, 1981; Hurd, 2003). Fortunately the first wave of the HRS contains a question that pertains directly to bequest motives by gauging the importance that respondents attach to leaving a bequest. Specifically, respondents were asked:

Some people think it is important to leave an inheritance to their surviving heirs, while others don't. Do you (both) feel it is very important, somewhat important, or not at all important, (or do you differ in how important it is)?

Figure 6 contrasts the responses to this question for inheriting and non-inheriting respondents. $^{7}$

\section{FIGURE 6 HERE}

Figure 6 indicates that the experience of having inherited is indeed related to the importance that respondents attach to leaving a bequest. Higher proportions of inheritors than non-inheritors stated that leaving a bequest was "very important" (29 versus 25 percent) or "somewhat important (48 versus 45 percent). ${ }^{8}$ These patterns are consistent with the picture portrayed in Figure 5.

Not everyone was interviewed about bequests in Wave 1, only the person designated to provide information about household finances (the so-called "financial respondent"). This procedure was changed in Wave 2, when the spouse of the financial respondent was queried separately about his or her intent to bequeath. In addition, the

\footnotetext{
${ }^{7}$ Only 2.5 percent of the respondents reported disagreeing with their spouse about the importance of leaving a bequest, and we left them out of Figure 6. Expecting to leave a bequest and attaching importance to leaving a bequest are highly, though not perfectly, correlated; the correlation between the raw ordinal measures is 0.36 . Fewer than one out of eight households planning to leave a substantial bequest considered leaving a bequest "not at all important."

${ }^{8}$ Significance levels for one-tailed $t$-tests of inheritor/non-inheritor differences in bequest importance are as follows: 0.0379 ("very important"), 0.0865 ("somewhat important"), and 0.0003 ("not important").
} 
wording of the question was changed. Respondents were asked to use a number from 0 to 100 to indicate the chances that they would leave a bequest worth $\$ 10,000$ or more, and likewise for the chances that they would leave a bequest worth $\$ 100,000$ or more. Figure 7 contrasts responses to this question for inheritors and non-inheritors.

Figure 7 reinforces the earlier picture of inheritor/non-inheritor differences in bequest behavior and portrays large differences in the subjective probabilities of leaving a bequest between the two groups. ${ }^{9}$ For example, the reported chances of leaving a bequest of $\$ 100,000$ or more was, on average, more than twice as large for inheritors as for noninheritors (43 versus 19 percent).

\section{FIGURE 7 HERE}

Are the patterns reported above just a product of wealth differences? Receiving an inheritance places a household in a better position to bequeath. If this were the only driving force, inheritor/non-inheritor differences in the propensity to leave a bequest would largely disappear once net worth is controlled for. This is not the case, however, as Figure 8 shows.

Figure 8 is a diagrammatic representation of a nonparametric regression of the binary variable for bequest intention used in Table $1(1=$ yes, $0=$ no $)$ on household net worth, separately for inheritors and non-inheritors. ${ }^{10}$ The figure suggests that the stronger intent to bequeath among inheritors is not merely a manifestation of wealth; inheritor/non-inheritor differences persist even after controlling for net worth. Except for households in the lowest quartile, the inheritors' (wider) curve lies throughout above the non-inheritors' (thinner) curve. ${ }^{11}$

\footnotetext{
9 The unit of observation in Figure 7 is the household; individual responses are averaged within households.

${ }^{10}$ Figure 8 is produced from Cleveland's (1979) local regression method (LOWESS) of the binary variable for bequest intention on the hyperbolic sine of net worth. The hyperbolic sine function, $h(z)=\ln \left(z+\left(z^{2}+1\right)^{1 / 2}\right)$ is similar to a logarithm, except that it can be applied to negative values. For easier interpretation, the figure is drawn with net worth expressed in percentiles rather than in logs.

${ }^{11}$ In the lowest quartile for net worth, only 11 percent of inheritors planned to make a significant bequest,
} 


\section{FIGURE 8 HERE}

Figure 9 replicates what was done in Figure 8, except that it draws upon the questions dealing with bequest importance rather than with bequest intentions. It portrays a picture akin to that in Figure 8. The results concerning inheritor/non-inheritor differences in bequest importance persist after controlling for net worth. For convenience, we combine in Figure 9 the categories "very important" and "somewhat important". Except for respondents with low but positive net worth, and those at the very uppermost ranks of the net worth distribution (the $97^{\text {th }}$ percentile and higher), respondents who inherited tend to report placing more importance on leaving a bequest. ${ }^{12}$

\section{FIGURE 9 HERE}

A similar analysis based on the third HRS measure of intentions to bequeath - the subjective probabilities collected in Wave 2 and already shown in Figure 7 - reinforces the results from Figures 8 and 9. Figure 10 plots the bequest intentions for inheritors and non-inheritors, and shows that such intentions are stronger for the former than for the latter even after controlling for net worth.

\section{FIGURE 10 HERE}

\section{Does the amount of the inheritance matter for bequest intentions?}

So far we have shown that the experience of inheriting appears to increase the propensity to bequeath. We next investigate amounts, and find that the size of the intended bequest is related to the size of the inheritance: respondents who received large inheritances (\$100,000 or more) were more likely to plan to give large bequests $(\$ 100,000$ or more)

compared to 18 percent of non-inheritors. But there are only a few inheritors in this quartile (45), and the differences are not significant at conventional levels $(\hat{t}=-1.44)$.

${ }^{12}$ The inheritor/non-inheritor curves cross at about the $97.5^{\text {th }}$ percentile; beyond that a higher percentage of non-inheritors report that leaving a bequest is important. But among this subset of 48 households, the inheritor/non-inheritor difference is not statistically significant. 
compared to their counterparts who inherited less than $\$ 100,000$. Further (and as before), this result appears not to be simply the product of being able to afford giving a larger bequest by dint of having received a larger inheritance since net worth is being controlled for. The results are displayed in Figure 11, which was obtained as follows. We use the information from the HRS in which financial respondents who inherited money were asked to report the size of the inheritance and the year in which it was received. We adjust for price inflation by expressing all inheritance values in 1991 dollars. We also impute interest payments of 3 percent per year and add them to the inheritance amount. We then contrast the subjective probability of leaving a large bequest (worth $\$ 100,000$ or more) for households who received a large inheritance $(\$ 100,000$ or more) versus those who received a smaller one (less than $\$ 100,000$ ). Of the 1,472 households who inherited, a third (482) received an inheritance of $\$ 100,000$ or more. Because of the obvious connection between net worth and the probability of leaving a large bequest, we again employ the nonparametric regressions of bequest intentions on net worth. Figure 11 shows quite clearly that for any given level of net worth, the subjective probability of leaving a bequest worth $\$ 100,000$ or more is higher for inheritors who received a bequest worth $\$ 100,000$ or more than for inheritors who received a bequest worth less than $\$ 100,000$.

\section{FIGURE 11 HERE}

\section{Other Covariates}

Our results are robust to the addition of other covariates. The non-parametric regressions reported above control only for net worth, and clearly there are other variables that conceivably influence intended bequests. For example, Smith (1999) and Hurd and Smith (2001) use the HRS and Asset and Health Dynamics of the Oldest Old (AHEAD) data to explore bequest behavior, and they consider a variety of potential determinants of bequests in addition to wealth, including birth cohort, health, education, number of children, income, and demographic variables (race, ethnicity, and sex). We estimated regressions specified with a similar set of covariates, but we also included (while these earlier studies did not) past inheritances as a determinant of bequests. Our basic result - 
that having inherited increases the propensity to bequeath - is unaffected by the inclusion of these additional controls.

The main results from the consideration of additional covariates are exhibited in Figures 12 and 13, which show that - conditional on a standard list of covariates that have been associated with bequest behavior - the propensity to bequeath is positively associated with having inherited. Figure 12 is the conditional analog of the unconditional histogram in Figure 5, each Figure reveals the same qualitative story: having inherited is positively associated with the probability of leaving a sizeable bequest. Figure 13 is the conditional analog of the unconditional histogram in Figure 6, and, again, points to the same result, this time that having inherited is positively associated with the importance that respondents attach to leaving a bequest.

Each of the ordered probits upon which Figures 12 and 13 are derived indicates that the positive relationship between past inheritances and the propensity to bequeath is significant at the .01 level. (These regressions are reported in Appendix Tables 2 and 3.)

\section{FIGURES 12 \& 13 HERE}

Finally, Figure 14 is the "conditional" analogue of Figure 7. Like Figures 8 and 9, it shows that the basic finding - inheritors are more likely to intend to bequeath than noninheritors - holds up after introducing the standard set of controls commonly used in the recent literature. (The regressions that Figure 14 is based upon are contained in Appendix Tables 4 and 5.)

\section{Dollar Values of the Inheritance-Bequest Relationship}

How much larger is the dollar value of the intended bequest of inheritors compared to non-inheritors, conditioning on the covariates referred to above? We estimate that the average predicted expected bequest from Wave 2 of the HRS for households that did not inherit is $\$ 73,316$; for those who did inherit; it is nearly one-third larger $-\$ 96,786$. 
This estimation took some doing, since our measure of bequests is expressed in terms of probabilities of leaving benchmark values, not the dollar values themselves. Partly for the sake of convenience, and partly for the sake of providing a reckoning of bequests in dollar terms, we recorded the responses to the two bequest-probability questions ("What are the chances that you (or your husband/wife/partner) will leave an inheritance totaling $\$ 10,000$ [ $\$ 100,000]$ or more?”) and converted them to dollar values, using information from the distribution of past inheritances received in the HRS sample. (We describe our methods in detail in Appendix I - The Construction of Dollar Values for Intended Bequests.)

\section{FIGURE 14 HERE}

The exact source of the inheritance - be it the respondent's parents, the spouse's parents, or both - appears to matter little for the estimated dollar impact on intended household bequests (Figure 15. The regression is given in Appendix Table 6.) Conditioning on the standard list of controls, having inherited is associated with the same substantially increased intended bequests, regardless of the source of the inheritance.

This finding suggests that the inheritance-bequest connection is driven by channels of influence beyond, say, genetically driven correlations in personality or temperament. Barring any sort of extreme assortative mating, we might expect that if a heritable temperament were the sole impetus to the inheritance-bequest relationship then inheriting from one's own parents would have a stronger impact on the propensity to bequeath than inheriting from a spouse's parents. If anything, the figure suggests that the latter is slightly more powerful (though the difference is not statistically significant).

\section{FIGURE 15 HERE}

The pattern depicted in Figure 15 is reinforced upon an examination of separate regressions for samples of husbands and wives in a SURE regression of intended bequests on the covariates discussed above plus dummies indicating whether the inheritance was 
received from parents or from in-laws (regression results are reported in Appendix Table 7). The regression results suggest that the positive association between inheritances and intended bequests does not depend much upon the source of the inheritance: husbands whose wives inherited report increased intended bequests, for example, as do husbands who inherited from their own parents. These results are depicted in Figure 16.

One discernable difference revealed by Figure 16 is that the partial correlation of husbands' bequest plans with inheritances received is stronger than the corresponding partial correlation for wives. This finding is consistent with other evidence from the HRS based upon direct questions about motivations for familial transfers, which indicates that men appear to care more about traditions than women (Cox and Soldo (2004)).

\section{FIGURE 16 HERE}

\section{Descriptive Evidence from the HRS Panel}

So far our descriptions and depictions have been based upon cross sections from Waves 1 and 2 of the HRS. We now turn our attention to panel-based descriptive work, adding information from Waves 3 (fielded in 1996) through Wave 6 (from 2002). We do not dwell too much on Wave 1 at this juncture, because in that wave intended bequests were measured differently than in subsequent waves.

We start with the following question: Does a first-time inheritance precipitate a boost in intended bequests? Figure 17 reveals that the answer is yes: intended bequests among recent inheritors are more generous compared to those of their non-inheriting counterparts. The most dramatic contrast occurs between the 1996 wave and the 1998 wave, when recent inheritors revised their intended bequests upward by over $\$ 12,000$, while non-inheritors revised their intended bequests downward by about $\$ 5,000{ }^{13}$

\footnotetext{
${ }^{13}$ The panel evidence raises some interesting issues that deserve further attention. For instance, the lifecycle model predicts that with perfect capital markets and unbiased expectations of future inheritances, recent receipt of an inheritance would have no impact on intended bequests. Of course, it is possible for the receipt of an inheritance to represent a surprise for households. In fact, the "accidental bequests" model predicts that inheritances should be thought of as exogenous variations in household wealth. But there is a potential "traditions" angle here as well, which might be worthy of examination. Suppose that it is the
} 


\section{FIGURE 17 HERE}

As before, the pattern in Figure 17 is consistent with pure wealth effects. Figure 18 suggests, however, that there is more to the revisions of bequest plans in response to the receipt of inheritances than a mere wealth effect. The figure is a diagrammatic representation of a nonparametric regression of the difference in log bequests on the difference in $\log$ net worth (that is, $\ln B(t)-\ln B(t-1)$ regressed on $\ln W(t)-\ln W(t-1)$ where, in the latter case and as before, the hyperbolic sine function is used to transform negative values of $W$ ).

\section{FIGURE 18 HERE}

Figure 18 suggests some difference in the revision of bequest plans for recent inheritors versus non-inheritors, although a "recent inheritance" dummy included in a simple regression of differences in log bequests on log net worth is insignificant.

What do panel estimates, controlling for the host of time-varying covariates discussed earlier, suggest about the relationship between intended bequests and the receipt of inheritance? We estimated a fixed-effects regression for the sample of HRS financial respondents who did not receive any inheritance prior to Wave 2. The results are reported in Appendix Table 8. The main conclusion from this regression is that having recently inherited is associated with an upward revision in intended bequests, though the revision appears to attenuate with time. The results are displayed in Figure 19. Having inherited in the current wave (conditional on net worth, income and the other covariates included in Appendix Table 8) is associated with an upward revision in intended bequests of a little more than $\$ 10,000$ (the mean intended bequest is $\$ 82,000$ ).

\footnotetext{
"gestalt" of inheritance receipt that solidifies family traditions, in the sense that traditions are an "experience good." We might then expect that the actual arrival of an inheritance affects bequest plans, even if capital markets are perfect and expectations about inheritances are unbiased. Another avenue worthy of consideration is how the expectation of receiving an inheritance figures into the "family traditions" approach. The HRS has information about expected future inheritances, but so far we have not examined this information in detail.
} 
The figure suggests, though, that the partial correlation between revisions in intended bequests and inheritance tends to diminish, the further back in time the inheritance was received.

\section{FIGURE 19 HERE}

Is the association between intended bequests and inheritance durable, or is it merely transitory? Our estimates do not provide a definite answer. The estimated bequest-inheritance relationships from previous waves (depicted in the rightmost four bars in Figure 19) are jointly insignificantly different from zero. But, likewise, they are jointly insignificantly different from $\$ 10,000$. In fact, the model in which the effect of inheritance is allowed to vary depending on the time of its receipt is statistically indistinguishable from a constrained specification in which having inherited is forced to have a lasting effect on intended bequests. The constrained estimate is depicted by the horizontal line in Figure 19, and is associated with a value of $\$ 6,700$.

\section{Differential Propensities to Bequeath out of Wealth by Inheritance-Wealth Relationships}

In our discussion of the logic of family traditions, we predicted a different propensity to bequeath out of wealth, depending on the relationship between bequeathable wealth and the value of the inheritance received. One way to recapitulate this logic is to imagine three types of households:

- "Strivers:" those whose bequeathable wealth is less than the value of their inheritance.

- "Standard bearers:" those whose bequeathable wealth exceeds the value of their inheritance.

- “Traditionless:" those who never received an inheritance.

These terms are coined primarily for presentational purposes, and should not be taken too literally; they are meant to reflect the variation in the predicted difference in the sensitivity of intended bequests, depending on whether bequeathable wealth exceeds or 
falls short of the value of the inheritance received. Recall from section 4 that a change in the wealth of "strivers" could precipitate a discrete jump in intended bequests, whereas a change in the wealth of "standard bearers" is predicted to have a smaller impact on intended bequests. Once the "family tradition" is honored, increases in intended bequests exhibit diminishing marginal utility. (For instance, think of the extreme case in which all that the parent cares about is abiding by the tradition such that in the neighborhood of the value of the inheritance, and beyond, bequests become wealth inelastic.) Intuitively, the marginal propensity to bequeath out of wealth for "traditionless" households should fall somewhere between that of strivers and standard bearers.

We estimated a very simple pooled cross-section - time series random effects regression of intended bequests on a quadratic function of household net worth for three distinct sub-samples of households: those whose net worth is less than the value of their inheritance ("Strivers"); those whose net worth exceeded the value of their inheritance ("Standard Bearers") and those who never received an inheritance ("Traditionless"). The estimated bequest - net worth relationships are depicted in Figure 20. Consistent with the logic of family traditions set out in Section 4, Figure 20 depicts a steeper bequests/net worth profile for "Strivers" than for "Standard Bearers," with the profile of the "Traditionless" in-between. Additional details on the marginal propensity to bequeath out of net worth for these three sub-samples are provided in Figure 21, where we mark the value of the estimated marginal propensity to bequeath at median net worth values for the three groups. There are large differences: "Strivers" have a marginal propensity to bequeath of .42 ; "Standard Bearers" have a propensity of .11 , and the propensity of "Traditionless," is .31.

\section{Fixed effects estimates}

We replicated the calculations depicted in Figures 16 and 17 using a fixed effects specification for intended bequests. (The results from the fixed effects regression are given in Appendix Table 9.) The results - shown in Figure 22 - mirror those depicted in the earlier figures: namely, "Strivers" have the highest propensity to bequeath out of net 
worth, "Standard Bearers" have the lowest propensity to bequeath, and "Traditionless" have a propensity to bequeath that is in-between.

FIGURES 20, $21 \& 22$ HERE

\section{"Point-Blank" Information from a Special Module in the HRS}

When respondents from a special module of the HRS were asked whether they agree or disagree with the statement, "I do for my children what my parents did for me," twothirds agreed (Figure 23). This "point blank" approach to inferring motivation for behavior has considerable virtue in that it is exceedingly direct and simple. On the face of it, the evidence summarized and depicted in Figure 23 is consistent with a "family traditions" approach to intergenerational transfer behavior.

The information in the figure originates from a special module of the 2000 Wave (the fifth wave) of the Health and Retirement Study, called "Benevolence and Obligation," which directly queries respondents about how they see their role as familial helpers, and what their concerns and motivations are for providing help to relatives. Like all experimental modules in the HRS, this one too consists of a random subset of all core self interviews in a given wave. In 2000, about one out of 12 households was assigned "Benevolence and Obligation," and only one person from the household answered the module questions. ${ }^{14}$ Figure 23 summarizes the responses of 418 respondents.

Of course, the problem with such a simple question is how to interpret the responses to it. For instance, suppose respondents inferred that the question had something to do with capabilities (that is, budget constraints) rather than with inclinations (that is, attributes of the utility function). A respondent who says "Yes, I do for my kids what my parents did for me," might simply be suggesting that he can afford to do certain things, so that having two-thirds in agreement with the statement could simply be an artifact of intergenerational correlations in incomes rather than in tastes. (A zero percent agreement rate would have been much more informative about "family traditions," in the

\footnotetext{
${ }^{14}$ There were 11 other special modules in the 2000 wave of the HRS, including modules about economic and social altruism. No respondent answered more than one module.
} 
sense that, from what we know about the preponderance of the forces that tilt respondents to agree, if they nevertheless were to disagree, it would be quite unlikely for traditional behavior to hold much sway in governing bequest behavior.)

FIGURE 23 HERE

\section{Additional reflections and further implications of "family traditions"}

\subsection{A historical case study}

If inheritance experience bears importantly on bequest behavior, we should be able to find evidence of bequest behavior that is in line with the inheritance experience, even when the law governing bequests changes. Indeed, if the maintenance of an inheritance tradition is all that important, we should expect the adjustment to a change in the law that governs bequests to come about largely through a change in variables other than bequest practices.

Consider an agriculture-based population in which primogeniture has been practiced for generations - a population of dynasties. With a constant supply of $N$ farms there are $N$ dynasties. The population is also characterized by a steady-state fertility pattern.

Under primogeniture, the children of a given family can be split into two groups: one group consists of the eldest son, $e$, who upon the parent's death will receive the family's entire estate. The other group consists all other children, $j$, none of whom will receive any of the estate. The fertility behavior of the $j$ children, who know that their own children will not inherit a farm either, can be expected to have factored in this eventuality. Child $e$, who in due course will inherit the family's entire estate, must be aware of his dynastic role as a "custodian" - recipient, holder, and "transferer" - of the family's estate. The fertility behavior of this child should also be expected to factor in the looming transfer predicament. 
Suppose now that new legislation is enacted, substituting the primogeniture rule with equal division of the estate among all children, and consider the fertility response of $j$ and $e$. The children of $j$ would not have inherited a farm under primogeniture and will not inherit a farm under equal sharing either (since $j$ were not in possession of farms in the first place). The new law should not then be expected to impact on the fertility behavior of $j$ one way or the other. Assuming that the law binds, $e$ will, however, now face a daunting dilemma: either replicate the past inheritance protocol or let the farm split as many ways as the number of children that he will have. When the "family traditions" effect is strong, an alteration in fertility behavior can be expected: if $e$ were to have only one son, the new inheritance law will not dent the dynasty's intergenerational transfer practice at all; if $e$ were to reduce fertility, the impact of the law would be mitigated.

The empirically testable prediction that emanates from this line of reasoning is that (in a period during which farming was practiced widely) provinces in which the ratio of $N$ to the total farming population was higher would have recorded a sharper fall in fertility upon the change in the inheritance law from primogeniture to equal sharing. Variation in fertility decline across provinces can be attributed to the varying extent by which the new law was binding in the provinces.

Although we were unable to marshal evidence that directly corroborates this prediction, we were able to find evidence that closely bears on it.

A series of legislative steps starting in 1793 at the French National Assembly and followed by Napoleon's Civil Code of 1804 dramatically changed the "grid" that had shaped French inheritance rules and practices ever since the Middle Ages: equal inheritance replaced strict impartibility. Students of the French family, especially Le Play ${ }^{15}$ and his followers in the middle of the nineteenth century, argued that "the adoption of the Civil Code in France, which strongly restricted testamentary freedom in favor of nearly equal inheritance prescribed by law was a decisive factor in explaining

\footnotetext{
15 The pioneering sociologist Le Play is described as someone "who was able to assess events more accurately than many of his contemporaries" and who, to the insights of contemporary thinkers, added "fieldwork with careful, empirically sound observations" (Parish and Schwartz, 1972).
} 
why the French birth rate was low. The argument was that when the peasant proprietor was faced with the prospect of being forced to divide his land among several children, he practiced family limitation ...". As a result a relatively high birth rate was maintained only in those areas where division was resisted" (Berkner and Mendels, 1978). An empirical study drawing on the French census of 1856, 1876, and 1901 and confined to départements (administrative units) that were predominantly rural and agricultural during the 1856-1901 period finds that "because stem families feared the new inheritance laws or because of tradition which preceded the Revolutionary laws, stem families reduce[d] fertility." (Parish and Schwartz, 1972), emphasis added. Stem families are families in which one child marries and stays within the household while the others leave, and that one child inherits the land.)

Evidence supporting the argument put forward by Le Play's followers that "the role of the eldest son in a preferential inheritance system was being replaced by an only son in a system of equal partibility" (Berkner and Mendels, 1978) seems to suggest then that, as predicted by our approach, families sought to maintain inheritance traditions even in an environment that had turned inhospitable to such a continuation.

Excluding the four most urban départements, thus confining attention to 82 rural départements in the first half of the nineteenth century, and assuming that the share of land-owning families in a département is closely positively correlated with the land tax per person in a département, there is evidence that marital fertility declined first and more in the "richest" départements (where richness is measured by land tax and "landed income"), while the poorest départements maintained high levels of marital fertility. Whereas "the factors stressed by demographic transition theory, primarily urbanization and industrialization, show no clear relation to fertility in the French départements at the time" (van de Walle, 1978), our approach suggests an explanation for the onset and the variability of the fertility decline. 


\subsection{Altruism, replication, and bequests}

Highlighting the role of family traditions in bequest behavior should not be interpreted as negating the role that altruism plays in prompting bequests. Yet even if altruism takes the center stage, the prediction of altruism for bequest behavior is modified, in a clearly discernible way, when family traditions are taken into account.

Consider the following simple way of incorporating the impact of the "family traditions" effect into a model of altruistic bequests, and of highlighting the difference between the prediction to which an unconstrained altruistic model gives rise and the prediction that emanates from an altruistic cum family traditions model. Let the utility function of an individual take the form of $U(c, b)=(1-\alpha) \ln c+\alpha \ln b$ where $U(\cdot)$ is twice differentiable and concave, $0<\alpha<1$ is the altruism weight, $c$ is the individual's lifetime consumption, $b$ is the bequest that the individual leaves, and $w=c+b$ is the individual's wealth, where all variables are expressed in present value terms. Since $\frac{\partial U}{\partial b}=-\frac{1-\alpha}{c}+\frac{\alpha}{b}$ (and $\frac{\partial^{2} U}{\partial b^{2}}=-\frac{1-\alpha}{c^{2}}-\frac{\alpha}{b^{2}}<0$ ), it follows that $b^{*}$, the optimal level of $b$, is $b^{*}=\alpha w$.

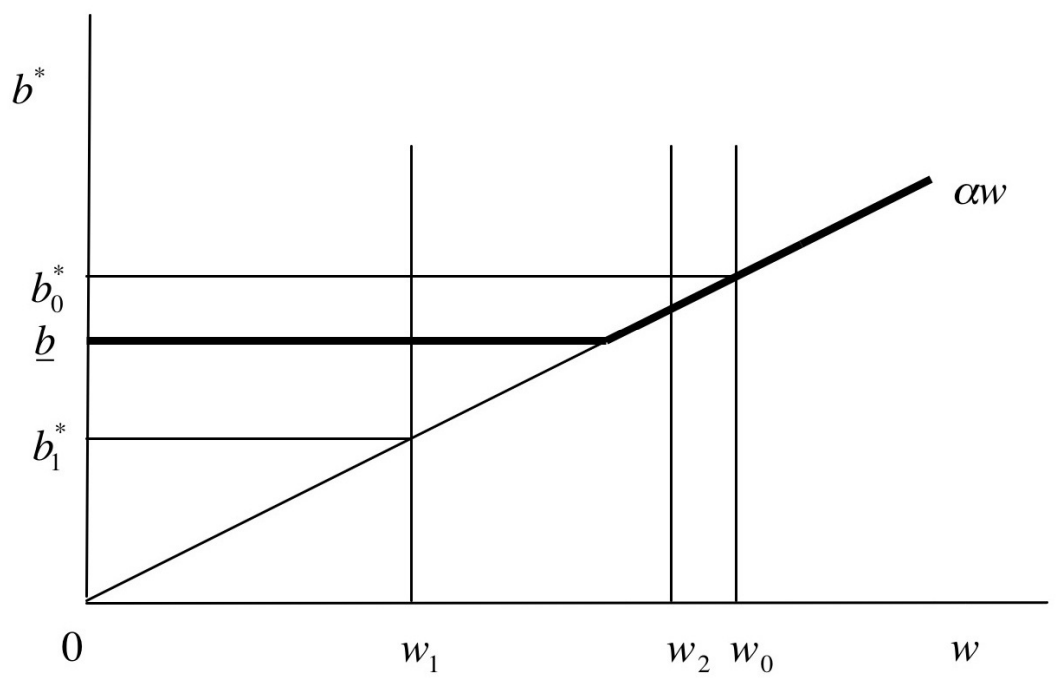

Figure 24. Altruism, replication, and bequests 
If the initial level of $w$ is $w_{0}$, bequests are set at $b_{0}^{*}$, and if the level of wealth declines to $w_{1}$, bequests are set at $b_{1}^{*}$.

The "family traditions" effect places a floor on bequests, say at $\underline{b}$. With the effect present, a wealth decline from $w_{0}$ to $w_{1}$ entails a decline in bequests by less than $\alpha \Delta w$, that is, only to $\underline{b}$. Of course, attenuation of the decline in the level of bequests will not arise for all reductions in wealth; it will not follow if wealth were to decline from $w_{0}$ to $w_{2}$, for example.

To further contrast the distinct roles of altruism and family traditions, suppose that the children's income is vulnerable to shocks, and that the impacts of the shocks is longlasting. If parents' bequests are motivated by altruism, a negative income shock for the children will likely result in a larger bequest, and a positive shock will likely result in a smaller bequest. Suppose, however, that bequests are governed by the "family traditions" effect. If the resources needed to "replicate" have not as yet been amassed, a positive income shock to the children's income will not diminish the effort to marshal the needed resources. Bequests will be less sensitive to a surge in the children's wealth when bequests are motivated by family traditions than when bequests are motivated by altruism.

One reason for the giving of bequests being conditioned by the receipt of inheritance could be dynastic altruism. If altruism is a trait that individuals receive and pass on (somewhat akin to a gene), then the altruism that guided $t$ in bequeathing to $t+1$ will likewise guide $t+1$ in bequeathing to $t+2$. While the possibility of altruism being an intergenerational inclination cannot be ignored (Stark, 1999) it is hard to see why altruism should consistently manifest itself in the specific form of bequests: we would expect altruism to give rise to $t$ giving to $t+1$, not to a particular type of giving by $t$. Moreover, if a high degree of dynastic altruism results in a dynasty creating and accumulating more wealth than a low degree of dynastic altruism (Falk and Stark, 2001) then altruism, wealth, and bequests will covary. Yet our data suggests that the correlation between the inheritance experience and the intention to bequeath is neither confined to nor more 
pronounced at high levels of wealth.

\subsection{Contrasting "the family traditions" effect with the strategic bequest motive}

The strategic bequest motive portrays a connection between the conduct of the $t+2$ generation children and bequests to them by $t+1$ : bequests are conceived as an expression of gratitude by $t+1$, a reward to $t+2$ for providing $t+1$ with attention and care. The family traditions motive suggests a connection between the conduct of $t$ towards $t+1$ and bequests made by $t+1$ to $t+2$ : in a way, inheritance received by $t+1$ gives rise to a gratitude which is expressed in the form of a corresponding bequest to $t+2$. The strategic motive forges a connection between children's conduct and parental bequest response: the replication motive points to no such connection.

\subsection{Implications for financial institutions}

Banks are keen to establish a presence where the demand for their products is high and presumably have long considered the wealth of their would-be customers a gauge of the business opportunities that await them. When "the family traditions" effect is strong, individuals' need for financial services in building up an estate is greater than when the effect is weak or absent. Interpreting our data as a general characterization of populations' attributes, populations tend to consist of inheritors and of non-inheritors, with the varying strength of "the family traditions" effect being higher for inheritors than for non-inheritors. In assessing the viability of particular markets and of the likely demand for specific financial products, banks may want to construct a weighted measure of the population's intent to bequeath and employ it as a co-predictor of the demand for their services.

\subsection{Giving to charity}

In a dynamic economy, the reason why the wealthy are more likely to give to 
charity than the less wealthy is not that the wealthy are wealthy. It is that the wealthy are more likely to have obeyed the family traditions "constraint" and are therefore freer to engage in charitable giving.

Compare the wealthy in Europe with the wealthy in the U.S. Two features stand out. First, the wealthy in Europe are less likely to give to charity than the wealthy in the U.S. Second, the wealthy in Europe are more likely to have their wealth originate in family firms. "The family traditions" effect provides a connection and an explanation. On average, the wealthy in the U.S. are more likely to have accumulated their fortunes in their own lifetime. On average, the wealthy in Europe are more likely to have inherited their wealth. Consequently, when it comes to the free disposition of wealth, the wealthy in Europe are more constrained by the mandate of "the family traditions" effect than their counterparts in the U.S. In a recent illuminating article based on a study by Thomson Financial commissioned by Newsweek, the magazine writes "Far more than Americans, Europeans consider it a tremendous failure to pass on a company worth less than when they inherited it." (Newsweek International, April 12, 2004, p. 45.) ${ }^{16}$

The July 31, 2004 issue of The Economist magazine ran a special report on philanthropy. Inter alia, the report makes the following disjoint observations: "on both sides of the Atlantic ... more and more people have more money than they want to leave to their kids;" "volunteering turns out to be particularly high in [several European countries]. In America, the balance between gifts of time and cash is more equal ... than in most of Europe;" "as the size of estates rises, the proportion going to heirs shrinks and the share left to charity increases;" "Could it be that today's rich think that [bequeathing] too much money harms their children? (pp. 48-50).” Although the report explains each observation separately, it falls short of providing a unifying reasoning. Our approach can provide such a reasoning.

The notion that "people have more money than they would like to leave to their

\footnotetext{
16 Thomson Financial was asked to compare the performance of family firms with the performance of nonfamily firms in Europe over a 10-year period ending in December 2003. The main finding of the study is that companies with public ownership and family control outperform nonfamily companies.
} 
kids" is questionable: it is unclear apriori why the additional money that people have should not be bequeathed to their children. Our approach suggests that it is not "more money" as such that prompts the giving (to charity) as opposed to bequeathing but, rather, that it is the composition by source of the available money wherein a higher fraction does not originate in inheritances. Given our perspective, perhaps the quote could be re-written: "people have more money than they feel bound to leave to their kids."

Indeed, a reason for volunteering being more prevalent in Europe than in the United States is that because of the higher incidence of wealth in Europe being a "dynastic wealth," given the inclination or the desire to give to others than to one's children, people in Europe are more constrained by their legacy of inheritance in bequeathing to others than to their children than people in the United States.

Our reasoning further implies then that the often-quoted main reason for Americans giving more to charities than Europeans may not be the "kinder tax treatment" in the United States.

Our approach also enables us to shed a different light on the observation that "as the size of estates rises, the proportion going to heirs shrinks." Our approach suggests that it is intertemporal variation, not cross-sectional variation, that accounts for the shifting of the relative weights. It is the rise in the size of the estates over time - which gives rise to a "surplus" of bequeathable wealth over inherited wealth - that facilitates a larger allocation to charitable giving, rather than a perception that "bequeathing too much may harm children."

\subsection{Poverty}

To a considerable extent, poverty is the juxtaposition of meager resources and a specific structure of incentives and inclinations. When people are very poor, they bequeath very little, and their children, in due time, have a tradition in hand of bequeathing very little. A lifetime incentive to amass resources so as to honor a tradition 
of bequeathing substantial amounts is absent. The poverty that people are born into - the paucity of the resources with which they start their productive life - is partly a result of the absolute poverty of their parents, and partly a result of their parents not having a tradition to honor - a state of affairs that originates from the parents' own inheritance experience. Put differently, poverty bites into the creation of a tradition that supports and invites intergenerational transfers of substantial resources. Thus, two effects are in place: there is little to bequeath (absence of wealth), and there is a tradition to bequeath a little (absence of a wealth-transferring tradition). Bequeathing depends both on wealth and on the experience of inheriting wealth. When people become wealthier, the impact of a tradition of transferring intergenerationally meager or no wealth could be attenuated. But, as already noted, it is also the case that a tradition of transferring little could forge a weak incentive to accumulate in order to transfer a lot. Thus, the paucity of resources and the lack of a tradition of transferring resources are mutually reinforcing: there is a stickiness of poverty across generations - yesterday's poverty becomes tomorrow's poverty.

\subsection{The extravagant consumption of the nouveau riche in Russia}

There is plenty of evidence that the nouveau riche in Russia, especially in Moscow, practice conspicuous consumption on an extravagant scale (U.S. Library of Congress, 2005). This behavior coincides with large sections of the Russian population becoming poorer. There is no culture in present-day Russia of community service and social responsibility, as the social attitudes of the Soviet era remain largely intact. The newly-acquired private wealth is not transferred to charitable ends.

In principle, only a little of the newly-acquired private wealth could have been consumed with the bulk earmarked for bequest purposes. Under the communist regime, the ownership of private property was prohibited, and there was no tradition in place of transferring private property intergenerationally. Thus, the prevailing extreme consumption behavior may partly be due to lack of a culture of social responsibility and moral restraint, and partly due to the absence of an inheritance experience and a bequest tradition. 


\section{Concluding remarks}

Our work suggests that the past is a prologue, in the sense that there exists a strong and robust relationship between inheritances received and intended bequests. While our investigation broaches several facets of the inheritance-bequest connection, there are several avenues for future research, based upon our approach.

For instance, it would be worth to examine the inheritance expectations data in the HRS. Such data impinge on the issues that interest us in several ways: expected inheritances could be counted as part of (expected) lifetime wealth, but what if an individual expects to receive an inheritance yet subsequently he receives nothing, or close to nothing? How would we expect intended bequests to be thereby altered? Receiving an unexpected inheritance may be much more akin to a variation in wealth. By contrast, receiving an expected inheritance could be a confirmation that a tradition is established or is maintained.

Inheritance is an endogenous variable, and some early models in the literature (for example, Tomes (1981)) envision bequests as compensatory, at least across generations, so that bequests respond in predictable ways to the wealth of the child generation. But instrumenting for inheritances is likely to be a dicey undertaking, and we have not as yet contemplated plausible candidates for key exogenous variables that might contribute to an instrumental variables approach. One countervailing argument is that, akin to the "accidental bequests" line of reasoning, much of the variation in inheritances is exogenous. But where would that leave our "family traditions" approach? One possible response is that traditions are captured in the "expected inheritance" variable, and perhaps this is the (endogenous) variable that in the RHS data belongs to the behavioral equation for intended bequests. Perhaps actual inheritances could serve as an instrument that is obviously correlated with expected inheritances but uncorrelated with error terms in an intended bequest equation, once wealth is duly controlled for. 
In a related vein, casual evidence suggests that there is more to the bequest story than merely "keeping up with the Joneses." An individual whose parents were too poor or too stingy to give much may be keen to reverse unsatisfactory familial patterns, a behavior that would run against the grain of the approach propounded in our paper.

These, and no doubt other related nuances, point nonetheless to the potential richness of our "traditions approach" for studying intergenerational transfers. Our results strongly suggest that researchers and policymakers should pay more attention to possible behavioral linkages between generations, and to the long-term implications of such linkages for one-time policy changes such as recent changes in the tax treatment of inheritances in the U.S. 


\section{References}

Andreoni, James (1989). "Giving with Impure Altruism: Applications of Charity and Ricardian Equivalence.” Journal of Political Economy 97, pp. 1447-1458.

Arrondel, Luc, Masson, Andre, and Pestieau, Pierre (1997). "Bequest and Inheritance: Empirical Issues and French-US Comparison." In Guido Erreygers and Toon Vandevelde (eds.), Is Inheritance Legitimate?, Springer-Verlag, Heidelberg, pp. 89125.

Arrondel, Luc and Masson, Andre (2001). "Family Transfers Involving Three Generations." Scandinavian Journal of Economics 103, pp. 415-443.

Barro, Robert J. (1974). "Are Government Bonds Net Wealth?" Journal of Political Economy 82, pp. 1095-1117.

Becker, Gary S. (1974). "A Theory of Social Interactions.” Journal of Political Economy 82, pp. 1063-94.

Becker, Gary S. (1992). "Habits, Addictions, and Traditions.” Kyklos 45, pp. 327-346.

Becker, Gary S. and Murphy, Kevin M. (1988). "A Theory of Rational Addiction." Journal of Political Economy 96, pp. 675-700.

Becker, Gary S. and Tomes, Nigel (1986). "Human Capital and the Rise and Fall of Families." Journal of Labor Economics 4, pp. S1-S39.

Behrman, Jere and Taubman, Paul (1990). "The Intergenerational Correlation between Children's Adult Earnings and Their Parents' Income: Results from the Michigan Panel Survey of Income Dynamics." Review of Income and Wealth 36, pp. 115-127.

Berkner, Lutz, K. and Mendels, Franklin F. (1978). "Inheritance Systems, Family Structure, and Demographic Patterns in Western Europe, 1700-1900." In Tilly, Charles (ed.), Historical Studies of Changing Fertility. Princeton: Princeton University Press, pp. 209-223.

Bernheim, B. Douglas, Lemke, Robert J., and Scholz, John Karl (2004). "Do Estate and Gift Taxes Affect the Timing of Private Transfers?" Journal of Public Economics 88, pp. 2617-2634.

Chiteji, Ngina S. and Stafford, Frank P. (1999). "Portfolio Choices of Parents and Their Children as Young Adults: Asset Accumulation by African-American Families." American Economic Review 89, pp. 377-380. 
Cleveland, William S. (1979). "Robust Locally Weighted Regression and Smoothing Scatterplots." Journal of the American Statistical Association 74, pp. 829-836.

Cox, Donald, and Soldo, Beth J. (2004). "Motivation for Financial Transfers and Care: Evidence from 'Point Blank' Survey Questions." Boston College Center for Retirement Research Working Paper No. 2004-17.

Cox, Donald and Stark, Oded (1996). "Intergenerational Transfers and the 'Demonstration Effect'." Boston College Working Paper No. 329.

Cox, Donald and Stark, Oded (2005). "On the Demand for Grandchildren: Tied Transfers and the Demonstration Effect." Journal of Public Economics 89, pp. 1665-1697.

Davies, James B. (1981). "Uncertain Lifetime, Consumption, and Dissaving in Retirement." Journal of Political Economy 89, pp. 561-577.

Falk, Ita and Stark, Oded (2001). "Dynasties and Destiny: On the Roles of Altruism and Impatience in the Evolution of Consumption and Bequests." Economica 68, pp. 505518.

Hamilton, William D. (1964). "The Genetical Theory of Social Behavior (I and II)." Journal of Theoretical Biology 7, pp. 1-32.

Hurd, Michael D. (2003). "Bequests: By Accident or by Design?" in Alicia Munnell and Annika Sunden (eds.), Death and Dollars: The Role of Gifts and Bequests in America, Washington, D.C.: Brookings Institution Press, pp. 93-118.

Hurd, Michael D. and Smith, James P. (2001). "Anticipated and Actual Bequests." in David Wise (ed.), Themes in the Economics of Aging, Chicago: University of Chicago Press, pp. 357-393.

Hurd, Michael and Smith, James P. (2002). "Expected Bequests and Their Distribution." RAND Labor and Population Program Working Paper No. DRU-3007.

Hurst, Erik and Charles, Kerwin K. (2003). "The Correlation of Wealth Across Generations.” Journal of Political Economy 111, pp. 1155-1182.

Jellal, Mohamed and Wolff, Francois-Charles (2002). "Altruistic Bequests with Inherited Tastes.” International Journal of Business and Economics 1, pp. 95-113.

Kotlikoff, Laurence J. and Summers, Lawrence H. (1981). "The Role of Intergenerational Transfers in Aggregate Capital Accumulation.” Journal of Political Economy 89, pp. 706-732.

McGarry, Kathleen (2001). "The Costs of Equality: Unequal Bequests and Tax Avoidance." Journal of Public Economics 79, pp. 179-204. 
Parish, William L. and Schwartz, Moshe (1972). "Household Complexity in Nineteenth Century France.” American Sociological Review 37, pp. 154-173.

Poterba, James (2001). "Estate and Gift Taxes and Incentives for Inter Vivos Giving in the U.S." Journal of Public Economics 79, pp. 237-264.

Smith, James P. (1999). "Inheritances and Bequests." in James P. Smith and Robert Willis (eds.), Wealth, Work, and Health: Innovations in Measurement in the Social Sciences, Ann Arbor: University of Michigan Press, pp. 121-149.

Stark, Oded (1999). "Siblings, Strangers, and the Surge of Altruism.” Economics Letters 65, pp. 135-142.

Thaler, Richard H. (1990). "Anomalies: Saving, Fungibility, and Mental Accounts." Journal of Economic Perspectives 4, pp. 193-205.

Tomes, Nigel (1981). "The Family, Inheritance, and the Intergenerational Transmission of Inequality." Journal of Political Economy 89, pp. 928-958.

U.S. Library of Congress, Federal Research Division (2005). Country Studies: Russia, Washington, D.C.

van de Walle, Etienne (1978). "Alone in Europe: The French Fertility Decline Until 1850." In Tilly, Charles (ed.), Historical Studies of Changing Fertility. Princeton: Princeton University Press, pp. 257-288.

Waldkirch, Andreas, Ng, Serena and Cox, Donald (2004) "Intergenerational Linkages in Consumption Behavior.” Journal of Human Resources, 39, pp. 355-381.

Wilhelm, Mark, Brown Eleanor, Rooney, Patrick and Steinberg, Richard (2004). "The Intergenerational Transmission of Generosity.” Indiana University-Purdue University Indianapolis Working Paper. 


\section{Appendix I - The construction of dollar values for intended bequests}

In the earlier part of the empirical work we discuss bequest measures that are expressed in terms that are not easy to value: concepts such as "leaving a significant bequest" or "attaching importance to leaving a bequest" are impossible to translate into dollar terms. The subjective probability measures associated with leaving a bequest of a particular size are more closely tied to dollar values, but they too are unwieldy for summarizing expected bequests. Accordingly, we combine the subjective probability measures with the distribution of actual inheritances received in order to construct a rough summary measure of the dollar value of expected bequests. An important caveat should be added at the outset. We are not seeking to gauge the actual distribution of expected bequests; to do so would require a procedure much more involved than the one we describe below. (See, for example, Hurd and Smith (2002).) Instead, we seek to construct an easy-to-interpret cardinal measure of expected bequests that is formulated in dollar terms. A good reason for doing this is to have in hand a bequest measure that can be adjusted for inflation once we proceed to the panel analysis. Another reason is to provide a measure that serves to indicate rough orders of magnitude of the impact of various covariates on expected bequests.

One may ask whether using the distribution of inheritances to assign dollar figures to bequests is not really mixing apples and pears. For instance, if an individual shares his father's bequest of $\$ 50,000$ equally with his sister, the individual's inheritance is only $\$ 25,000$. On the other hand, if the individual's wife also inherits (say, $\$ 30,000$ ) then the total (household) inheritances would be $\$ 55,000$. Only in an economy comprised of married couples with two children in stationary, steady-state equilibrium, would the distribution of inheritances match the distribution of bequests. To repeat, our use of the distribution of inheritances is only an expedient, and in future work we contemplate using a distribution of actual bequests to formulate imputed expected bequests.

Our measure is constructed as follows. Define $P^{10+}$ and $P^{100+}$ as the reported probabilities of leaving a bequest of $\$ 10,000$ or more, and of $\$ 100,000$ or more, 
respectively. Define $I_{\text {med }}^{10-100}$ as the median value of inheritances that are between $\$ 10,000$ and $\$ 100,000$ and $I_{\text {med }}^{100+}$ as the median value of inheritances over $\$ 100,000$. Our imputed dollar value of expected bequests is calculated as

$$
B_{\text {DOLLAR }}=P^{10+} \cdot I_{m e d}^{10-100}+P^{100+} \cdot\left(I_{m e d}^{100+}-I_{m e d}^{10+}\right)
$$

Appendix figure 1 displays the size distribution of $B_{D O L L A R}$, and Appendix figure 2 shows the size distribution of inheritances. For comparison purposes, the inheritances in Appendix figure 2 are top-coded at $I_{\text {med }}^{100+}$, which is $\$ 233,700$. The value of $I_{\text {med }}^{10-100}$ is $\$ 35,400$.

The distributions in Appendix figures 1 and 2 clearly differ. Part of the reason for the uneven distribution of imputed bequests in Appendix figure 1 stems from the tendency of respondents to bunch their reported subjective probabilities at round numbers such as 50 percent or 100 percent. The median imputed expected bequest (among those expecting to leave a non-zero bequest) is $\$ 93,100$, about double the median inheritance of $\$ 46,300$. 

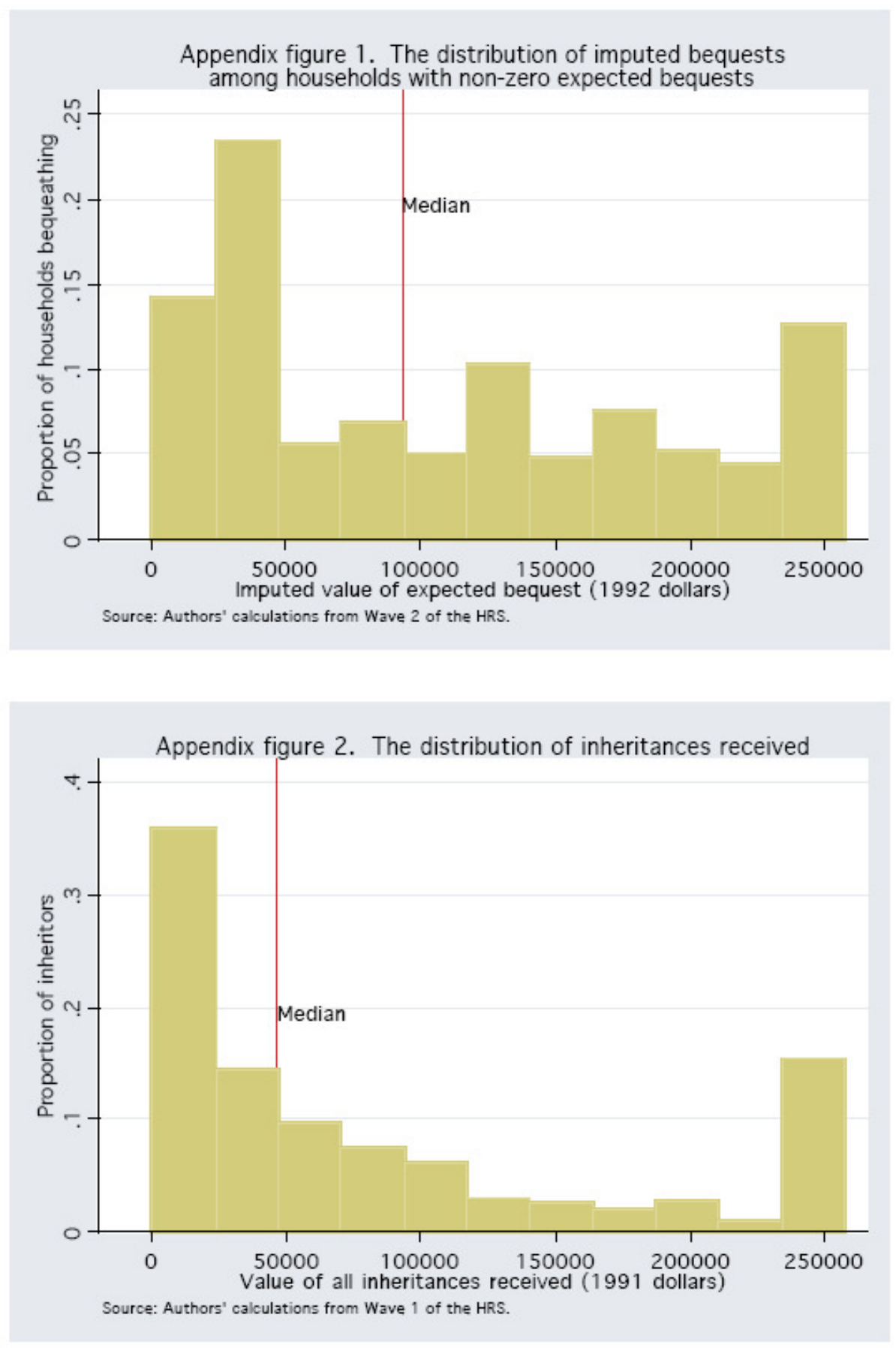


\section{Appendix II - Appendix Tables}

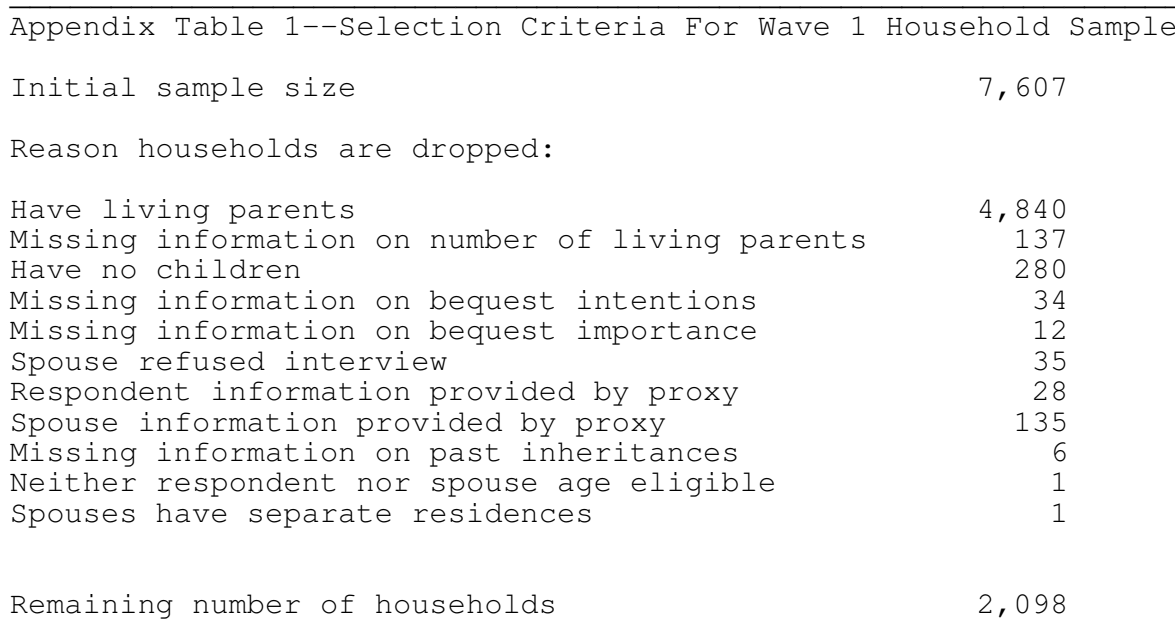

Source: Authors' calculations from Wave 1 of the HRS. 
Appendix Table 2. Regression of intent to bequeath on economic and demographic variables in addition to past inheritances

\begin{tabular}{|c|c|c|c|}
\hline Explanatory variable & $\begin{array}{c}\text { Estimated } \\
\text { coefficient }\end{array}$ & $\begin{array}{l}\text { Estimated } \\
\text { t-value }\end{array}$ & $\begin{array}{c}\text { Variable } \\
\text { mean }\end{array}$ \\
\hline Net worth (000's) & 0.0006 & 7.10 & 171.69 \\
\hline Household income (000's) & 0.0020 & 2.45 & 37.49 \\
\hline Pension wealth (000's) & 0.0004 & 1.81 & 65.94 \\
\hline Soc. sec. wealth $\left(000^{\prime} \mathrm{s}\right)$ & 0.0005 & 0.74 & 112.90 \\
\hline Resp. or $\mathrm{Sp}$. retired (1=yes) & 0.1010 & 1.34 & 0.22 \\
\hline No worker in hh ( $1=$ yes) & -0.1690 & -2.48 & 0.27 \\
\hline Two workers in hh ( $1=y e s)$ & -0.1007 & -1.30 & 0.19 \\
\hline HH has pension ( $1=$ yes) & 0.0394 & 0.55 & 0.66 \\
\hline HH has DC pension ( 1 =yes) & 0.1233 & 2.02 & 0.36 \\
\hline Years of education, Resp. & -0.0055 & -0.55 & 11.46 \\
\hline Married ( $1=$ yes) & -0.1955 & -0.94 & 0.52 \\
\hline Cohabiting $(1=$ yes $)$ & 0.1021 & 0.35 & 0.01 \\
\hline Separated ( $1=$ yes $)$ & -0.0763 & -0.42 & 0.07 \\
\hline Divorced ( 1 =yes) & -0.1336 & -0.80 & 0.22 \\
\hline Widowed ( $1=$ yes $)$ & 0.0178 & 0.10 & 0.15 \\
\hline Female respondent ( 1 =yes) & -0.0946 & -1.72 & 0.54 \\
\hline Age of respondent & -0.0020 & -0.31 & 57.93 \\
\hline Max. life expectancy, age 70 & 0.0015 & 1.18 & 68.81 \\
\hline Max. life expectancy, age 80 & 0.0008 & 0.74 & 47.68 \\
\hline Resp. health exclnt. ( 1 =yes) & 0.3180 & 2.93 & 0.17 \\
\hline Resp. health v. good ( $1=$ yes) & 0.3175 & 3.13 & 0.26 \\
\hline Resp. health good ( 1 =yes) & 0.2496 & 2.56 & 0.29 \\
\hline Resp. health fair ( $1=$ yes) & 0.1500 & 1.50 & 0.17 \\
\hline Sp. health excellent ( 1 =yes) & -0.0076 & -0.05 & 0.10 \\
\hline Sp. health v. good ( 1 =yes) & 0.1156 & 0.81 & 0.14 \\
\hline Sp. health good ( $1=$ yes) & 0.0884 & 0.64 & 0.16 \\
\hline Sp. health fair ( $1=y e s)$ & 0.0795 & 0.55 & 0.09 \\
\hline No. of kids & -0.0104 & -0.36 & 3.63 \\
\hline No. of low-income kids & -0.0325 & -0.88 & 0.68 \\
\hline No. of middle-income kids & -0.0981 & -2.90 & 1.08 \\
\hline No. of high-income kids & -0.0717 & -2.19 & 1.23 \\
\hline No. of kids within 10 miles & 0.0250 & 1.19 & 1.25 \\
\hline Rec'd inheritance ( $1=y e s)$ & 0.2299 & 3.87 & 0.24 \\
\hline Constant & -0.3084 & -0.72 & 1.00 \\
\hline
\end{tabular}

Dependent variable count--Intent to leave substantial bequest

$\begin{array}{lll}\text { Yes, definitely } & (=5) & 234 \\ \text { Yes, probably } & (=4) & 292 \\ \text { Yes, possibly } & (=3) & 303 \\ \text { No, probably } & (=2) & 538 \\ \text { No, definitely } & (=1) & 696\end{array}$

Pseudo R-squared

Number of observations

Source: Authors' calculations using Wave 1 of the HRS. 
Appendix Table 3. Regression of importance of leaving a bequest on economic and demographic variables in addition to past inheritances

\begin{tabular}{|c|c|c|c|}
\hline Explanatory variable & $\begin{array}{c}\text { Estimated } \\
\text { coefficient }\end{array}$ & $\begin{array}{l}\text { Estimated } \\
\text { t-value }\end{array}$ & $\begin{array}{c}\text { Variable } \\
\text { mean }\end{array}$ \\
\hline Net worth (000's) & 0.0002 & 2.39 & 169.57 \\
\hline Household income (000's) & 0.0010 & 1.04 & 37.38 \\
\hline Pension wealth (000's) & 0.0001 & 0.41 & 65.85 \\
\hline Soc. sec. wealth (000's) & -0.0009 & $-1 \cdot 35$ & 111.92 \\
\hline Resp. or $\mathrm{Sp}$. retired (1=yes) & 0.0015 & 0.02 & 0.22 \\
\hline No worker in hh ( $1=$ yes) & 0.0742 & 1.04 & 0.27 \\
\hline Two workers in hh ( $1=y e s)$ & -0.0379 & -0.46 & 0.18 \\
\hline $\mathrm{HH}$ has pension ( $1=$ yes) & -0.0605 & -0.82 & 0.66 \\
\hline $\mathrm{HH}$ has DC pension ( 1 =yes) & 0.0418 & 0.65 & 0.36 \\
\hline Years of education, Resp. & -0.0102 & -0.98 & 11.46 \\
\hline Married ( $1=$ yes) & -0.0393 & -0.18 & 0.51 \\
\hline Cohabiting ( 1 =yes $)$ & 0.1471 & 0.47 & 0.01 \\
\hline Separated ( $1=y e s)$ & 0.0524 & 0.28 & 0.08 \\
\hline Divorced ( 1 =yes) & -0.1004 & -0.59 & 0.23 \\
\hline Widowed ( $1=$ yes $)$ & -0.0686 & -0.39 & 0.15 \\
\hline Female respondent ( $1=$ yes) & -0.0936 & -1.62 & 0.54 \\
\hline Age of respondent & 0.0149 & 2.18 & 57.92 \\
\hline Max. life expectancy, age 70 & 0.0019 & 1.45 & 68.81 \\
\hline Max. life expectancy, age 80 & 0.0008 & 0.75 & 47.64 \\
\hline Resp. health exclnt. ( 1 =yes) & -0.0214 & -0.19 & 0.17 \\
\hline Resp. health v. good ( $1=$ yes) & -0.0394 & -0.38 & 0.26 \\
\hline Resp. health good ( $1=$ yes) & 0.0178 & 0.18 & 0.29 \\
\hline Resp. health fair ( $1=$ yes) & -0.0414 & -0.41 & 0.17 \\
\hline Sp. health excellent ( 1 =yes) & -0.1541 & -0.95 & 0.09 \\
\hline Sp. health v. good ( $1=$ yes $)$ & -0.1286 & -0.84 & 0.14 \\
\hline Sp. health good ( $1=$ yes) & -0.0331 & -0.22 & 0.16 \\
\hline Sp. health fair ( $1=$ yes) & 0.0092 & 0.06 & 0.09 \\
\hline No. of kids & 0.0488 & 1.60 & 3.63 \\
\hline No. of low-income kids & -0.0904 & -2.39 & 0.68 \\
\hline No. of middle-income kids & -0.1117 & -3.18 & 1.09 \\
\hline No. of high-income kids & -0.1489 & -4.35 & 1.22 \\
\hline No. of kids within 10 miles & 0.0367 & 1.71 & 1.25 \\
\hline Rec'd inheritance ( 1 =yes) & 0.2455 & 3.91 & 0.24 \\
\hline Constant & 0.0494 & 0.11 & 1.00 \\
\hline
\end{tabular}

Dependent variable count--Importance of leaving a bequest

$\begin{array}{llr}\text { Very important } & (=3) & 520 \\ \text { Somewhat important } & (=2) & 922 \\ \text { Not important } & (=1) & 569\end{array}$

Pseudo R-squared

Number of observations

0.021

1,976

Source: Authors' calculations using Wave 1 of the HRS. 


\begin{tabular}{|c|c|c|c|}
\hline \multicolumn{4}{|c|}{$\begin{array}{r}\text { Appendix Table 4. Two-limit Tobit estimates } \\
\text { subjective probability of making a bequest } \\
\text { of } \$ 10,000 \text { or more }\end{array}$} \\
\hline & $\begin{array}{l}\text { Estimated } \\
\text { coefficient }\end{array}$ & $\begin{array}{c}\text { Estimated } \\
\text { t-value }\end{array}$ & $\begin{array}{l}\text { Variable } \\
\text { mean }\end{array}$ \\
\hline \multicolumn{4}{|l|}{ Explanatory variable } \\
\hline Net worth (000's) & 0.0007 & 6.67 & 189.09 \\
\hline Income $(000 ' s)$ & 0.0009 & 1.42 & 42.70 \\
\hline Pension wealth (000's) & 0.0007 & 3.60 & 74.62 \\
\hline Soc. sec. wealth (000's) & 0.0025 & 3.96 & 115.92 \\
\hline Resp. or $\mathrm{Sp}$. retired (1=yes) & 0.0640 & 0.90 & 0.27 \\
\hline No worker in hh ( $1=$ yes $)$ & -0.0519 & -0.82 & 0.34 \\
\hline Two workers in hh (1=yes) & 0.0025 & 0.03 & 0.18 \\
\hline $\mathrm{HH}$ has pension ( 1 =yes) & 0.2679 & 4.08 & 0.45 \\
\hline HH has DC pension ( 1 =yes) & -0.0614 & -0.87 & 0.24 \\
\hline Married $(1=$ yes $)$ & -0.2929 & -1.54 & 0.55 \\
\hline Divorced/Sep. ( 1 =yes $)$ & -0.0016 & -0.01 & 0.27 \\
\hline Widowed ( 1 =yes) & 0.1090 & 0.68 & 0.15 \\
\hline Female respondent ( 1 =yes) & -0.2939 & -3.42 & 0.89 \\
\hline Age of Respondent & -0.0174 & -2.49 & 56.46 \\
\hline Max. life expectancy, age 70 & 0.0036 & 3.20 & 66.85 \\
\hline Max. life expectancy, age 80 & 0.0000 & 0.05 & 46.43 \\
\hline Resp. health exclnt. ( 1 =yes) & 0.6870 & 5.93 & 0.13 \\
\hline Resp. health v. good ( 1 =yes) & 0.5983 & 5.80 & 0.29 \\
\hline Resp. health good ( 1 =yes) & 0.4524 & 4.55 & 0.31 \\
\hline Resp. health fair ( $1=y e s)$ & 0.3031 & 2.96 & 0.17 \\
\hline Sp. health excellent ( $1=$ yes) & 0.0739 & 0.52 & 0.08 \\
\hline Sp. health v. good ( $1=$ yes $)$ & 0.1137 & 0.90 & 0.16 \\
\hline Sp. health good ( $1=$ yes $)$ & 0.1152 & 0.92 & 0.16 \\
\hline Sp. health fair ( $1=y e s)$ & 0.0897 & 0.69 & 0.10 \\
\hline Number of kids & -0.0464 & -2.56 & 3.50 \\
\hline No. of low-income kids & -0.0397 & $-1 \cdot 22$ & 0.32 \\
\hline No. of middle-income kids & -0.0362 & -1.39 & 0.72 \\
\hline No. of high-income kids & 0.0645 & 3.27 & 1.46 \\
\hline No. of kids within $10 \mathrm{mi}$. & 0.0111 & 0.54 & 1.18 \\
\hline Rec'd inheritance ( $1=y e s)$ & 0.2827 & 4.92 & 0.25 \\
\hline Constant & 0.740 & 1.73 & 1.00 \\
\hline Dependent variable mean & & 0.594 & \\
\hline Pseudo R-squared & & 0.158 & \\
\hline Number of observations & & 783 & \\
\hline
\end{tabular}

Source: Authors' calculations using Wave 2 of the HRS.

Note: The term 'Respondent' refers to the person in the household who answered the family-related questions (the so-called 'Section E' Respondent) in the first two waves of the HRS. The dependent variable is the section E Respondent's subjective probability of leaving a bequest of $\$ 10,000$ or more. 


\begin{tabular}{|c|c|c|c|}
\hline \multicolumn{4}{|c|}{$\begin{array}{r}\text { Appendix Table 5. Two-limit Tobit estimates a } \\
\text { subjective probability of making a bequest } \\
\text { of } \$ 100,000 \text { or more }\end{array}$} \\
\hline & $\begin{array}{c}\text { Estimated } \\
\text { coefficient }\end{array}$ & $\begin{array}{l}\text { Estimated } \\
\text { t-value }\end{array}$ & $\begin{array}{l}\text { Variable } \\
\text { mean }\end{array}$ \\
\hline \multicolumn{4}{|l|}{ Explanatory variable } \\
\hline Net worth (000's) & 0.0007 & 7.83 & 189.09 \\
\hline Income $(000 ' s)$ & 0.0025 & 3.90 & 42.70 \\
\hline Pension wealth (000's) & 0.0004 & 2.55 & 74.62 \\
\hline Soc. sec. wealth (000's) & 0.0015 & 2.30 & 115.92 \\
\hline Resp. or Sp. retired (1=yes) & -0.0119 & -0.16 & 0.27 \\
\hline No worker in hh ( 1 =yes) & 0.0140 & 0.20 & 0.34 \\
\hline Two workers in hh (1=yes) & -0.1896 & -2.41 & 0.18 \\
\hline $\mathrm{HH}$ has pension ( $1=$ yes $)$ & 0.1852 & 2.74 & 0.45 \\
\hline $\mathrm{HH}$ has DC pension ( 1 =yes) & -0.0180 & -0.25 & 0.24 \\
\hline Married $(1=y e s)$ & -0.1877 & -0.83 & 0.55 \\
\hline Divorced/Sep. (1=yes) & 0.0801 & 0.43 & 0.27 \\
\hline Widowed $(1=$ yes $)$ & 0.0812 & 0.42 & 0.15 \\
\hline Female respondent ( 1 =yes) & -0.2715 & -2.91 & 0.89 \\
\hline Age of Respondent & -0.0215 & -2.86 & 56.46 \\
\hline Max. life expectancy, age 70 & 0.0011 & 0.86 & 66.85 \\
\hline Max. life expectancy, age 80 & 0.0019 & 1.67 & 46.43 \\
\hline Resp. health exclnt. ( 1 =yes) & 0.7184 & 5.19 & 0.13 \\
\hline Resp. health v. good ( $1=$ yes) & 0.6123 & 4.73 & 0.29 \\
\hline Resp. health good ( 1 =yes) & 0.3762 & 2.96 & 0.31 \\
\hline Resp. health fair ( 1 =yes) & 0.2615 & 1.96 & 0.17 \\
\hline Sp. health excellent ( 1 =yes) & 0.4234 & 2.71 & 0.08 \\
\hline Sp. health v. good $(1=y e s)$ & 0.3881 & 2.67 & 0.16 \\
\hline Sp. health good ( 1 =yes) & 0.3529 & 2.43 & 0.16 \\
\hline Sp. health fair ( $1=y e s)$ & 0.0835 & 0.54 & 0.10 \\
\hline Number of kids & -0.0455 & -2.17 & 3.50 \\
\hline No. of low-income kids & -0.0179 & -0.43 & 0.32 \\
\hline No. of middle-income kids & -0.0490 & -1.60 & 0.72 \\
\hline No. of high-income kids & 0.0967 & 4.33 & 1.46 \\
\hline No. of kids within $10 \mathrm{mi}$. & -0.0222 & -0.95 & 1.18 \\
\hline Rec'd inheritance ( 1 =yes) & 0.2910 & 5.07 & 0.25 \\
\hline Constant & 0.093 & 0.20 & 1.00 \\
\hline Dependent variable mean & & 0.274 & \\
\hline $\begin{array}{l}\text { Pseudo R-squared } \\
\text { Number of observations }\end{array}$ & & 0.190 & \\
\hline
\end{tabular}

Source: Authors' calculations using Wave 2 of the HRS.

Note: The term 'Respondent' refers to the person in the household who answered the family-related questions (the so-called 'Section E' Respondent) in the first two waves of the HRS. The dependent variable is the section E Respondent's subjective probability of leaving a bequest of $\$ 100,000$ or more. 
Appendix Table 6. OLS estimates of the effects of inheritances on intended bequests

\begin{tabular}{|c|c|c|c|}
\hline & $\begin{array}{l}\text { Estimated } \\
\text { coefficient }\end{array}$ & $\begin{array}{c}\text { Estimated } \\
\text { t-value }\end{array}$ & $\begin{array}{c}\text { Variable } \\
\text { mean }\end{array}$ \\
\hline \multicolumn{4}{|l|}{ Explanatory variable } \\
\hline Net worth $\left(000^{\prime} \mathrm{s}\right)$ & 77.75 & 14.50 & 188.95 \\
\hline Income $\left(000^{\prime} \mathrm{s}\right)$ & 53.05 & 2.43 & 43.37 \\
\hline Pension wealth (000's) & 51.18 & 4.59 & 75.71 \\
\hline Soc. sec. wealth $\left(000^{\prime} \mathrm{s}\right)$ & 127.04 & 3.25 & 116.05 \\
\hline Resp. or $\mathrm{Sp}$. retired ( $1=y e s)$ & 2551.40 & 0.57 & 0.28 \\
\hline No worker in hh (1=yes) & 2375.91 & 0.59 & 0.34 \\
\hline Two workers in hh (1=yes) & -9583.63 & -1.93 & 0.18 \\
\hline $\mathrm{HH}$ has pension ( 1 =yes) & 13906.05 & 3.36 & 0.46 \\
\hline HH has DC pension ( 1 =yes) & -2765.92 & -0.62 & 0.24 \\
\hline Married ( $1=y e s)$ & -7675.27 & -0.65 & 0.55 \\
\hline Divorced/Sep. (1=yes) & 2309.53 & 0.24 & 0.27 \\
\hline Widowed ( $1=$ yes) & 1654.48 & 0.17 & 0.15 \\
\hline Female respondent ( $1=$ yes) & -9001.34 & -2.62 & 0.52 \\
\hline Age of Respondent & -1386.84 & -3.30 & 57.68 \\
\hline Max. life expectancy, age 70 & 58.01 & 0.81 & 66.78 \\
\hline Max. life expectancy, age 80 & 79.77 & 1.23 & 46.36 \\
\hline Resp. health exclnt. (1=yes) & 47686.85 & 6.92 & 0.14 \\
\hline Resp. health v. good ( $1=$ yes) & 34681.01 & 5.60 & 0.27 \\
\hline Resp. health good ( 1 =yes) & 17103.10 & 2.89 & 0.30 \\
\hline Resp. health fair (1=yes) & 12410.85 & 2.06 & 0.18 \\
\hline sp. health excellent ( $1=$ yes) & 22825.71 & 2.61 & 0.08 \\
\hline sp. health v. good (1=yes) & 14191.61 & 1.82 & 0.18 \\
\hline sp. health good ( $1=y e s)$ & 10147.56 & 1.29 & 0.16 \\
\hline Sp. health fair ( $1=$ yes) & -11617.40 & -1.37 & 0.08 \\
\hline Number of kids & -1757.74 & -1.55 & 3.50 \\
\hline No. of low-income kids & 160.28 & 0.08 & 0.32 \\
\hline No. of middle-income kids & -3586.20 & -2.22 & 0.71 \\
\hline No. of high-income kids & 5134.35 & 4.14 & 1.46 \\
\hline No. of kids within $10 \mathrm{mi}$. & -1809.77 & -1.41 & 1.17 \\
\hline Only Resp. inher ( $1=$ yes) & 23094.74 & 5.81 & 0.19 \\
\hline Only sp. inher ( $1=y e s)$ & 26813.17 & 3.14 & 0.03 \\
\hline Both $R \& S$ inher ( $1=y e s)$ & 22113.75 & 2.38 & 0.03 \\
\hline Constant & 87407.02 & 3.28 & 1.00 \\
\hline Dependent variable mean & \multicolumn{3}{|c|}{79,131} \\
\hline $\begin{array}{l}\text { R-squared } \\
\text { Number of observations }\end{array}$ & \multicolumn{3}{|c|}{$\begin{array}{c}0.419 \\
1,800\end{array}$} \\
\hline
\end{tabular}

Source: Authors' calculations from Wave 2 of the HRS. 
Appendix Table 7. Intended bequests of husbands versus wives: SURE estimates of the effects of inheritances from parents versus in-laws

Husbands

Explanatory variable

Net worth (000's)

Husband's inc (000's)

Wife's inc $(000$ 's)

Husb retired ( $1=y e s)$

Wife retired (1=yes)

Husb. working ( $1=y e s)$

Wife working ( 1 =yes)

Husb has pens ( $1=y e s)$

Wife has pens ( $1=$ yes)

Husband's age

Wife's age

H's life exp, 70

W's life exp, 70

H's life exp, 80

W's life exp, 80

H's hlth exlnt ( 1 =yes)

H's hlth $v$ gd ( 1 =yes)

H's hlth gd (1=yes)

H's hlth fr (1=yes)

W's hlth exlnt ( $1=y e s)$

W's hlth $\mathrm{v}$ gd ( 1 =yes)

W's hlth gd (1=yes)

W's hlth fr (1=yes)

No. of poor kids

No. of mid-inc. kids

No. of hi-inc. kids

No. of kids in $10 \mathrm{mi}$.

Only $\mathrm{H}$ inher ( $1=y e s)$

Only $W$ inher ( $1=y e s)$

Both $\mathrm{H} \& W$ inher (1=yes)

Constant

Dependent variable mean

$\mathrm{R}$-squared

Number of observations

Coeff.
79.97
582.50
438.70
7999.34
0901.12
1998.37
1226.84
4454.58
2905.48
-757.05
727.63
301.72
14.36
-216.83
-14.15
6865.08
5092.29
5643.18
9743.90
2571.66
21741.72
1988.35
-8062.92
1401.54
9021.43
3742.59
7323.29
7694.70
17618.89
31727.56
32309.01

t-val

8.34

5.02

1.62

0.84

1.17

$-0.22$

$-0.16$

$-0.66$

$-0.37$

$-0.77$

0.83

1.91

0.09

$-1.56$

$-0.11$

1.48

1.44

0.34

0.57

1.34

1.38

0.78

$-0.48$

$-0.33$

$-3.08$

1.73

$-2.83$

2.11

2.03

2.62

0.56

112,834

0.349

649
Wives

Coeff. t-val.

6.28

62.34

391.23

350.88

8105.52

$-7605.14$

7242.12

$-16137.70$

2370.17

4602.61

576.12

$-541.69$

177.03

134.53

$-202.55$

295.43

50765.53

41597.77

42352.27

18546.19

11216.25

11237.51

$-9183.72$

$-15412.64$

$-2074.88$

$-4275.43$

7170.56

$-1258.19$

19764.83

23272.87

21330.28

$-14145.84$

3.25

1.25

0.82

$-0.79$

0.77

$-2.03$

0.34

0.56

0.56

$-0.60$

1.08

0.79

$-1.41$

2.12

2. 71

2.31

2.43

1.05

0.65

0.69

$-0.58$

$-0.88$

$-0.47$

$-1.41$

3.20

$-0.47$

2.28

2.59

1.70

$-0.24$

99,868

0.291

649

0.42
113.26

113.26
Variable mean

267.27

30.50

11.13

0.28

0.16

0.64

0.53

0.45

0.33

58.15

55.67

63.75

64.75

37.04

40.26

0.18

0.33

0.29

0.16

0.16

0.37

0.33

0.10

0.23

0.72

1.65

1.16

0.15

0.14

0.07

1.00

Estimated husband-wife correlation in residuals

Chi-squared statistic for correlation in residuals

Source: Authors' calculations using Wave 2 of the HRS. 
Appendix Table 8. The importance of leaving a bequest: Fixed effects estimates of the effects of economic and demographic variables in addition to past inheritances

\begin{tabular}{|c|c|c|c|}
\hline & $\begin{array}{c}\text { Estimated } \\
\text { coefficient }\end{array}$ & $\begin{array}{c}\text { Estimated } \\
t \text {-value }\end{array}$ & $\begin{array}{c}\text { Variable } \\
\text { mean }\end{array}$ \\
\hline \multicolumn{4}{|l|}{ Explanatory variable } \\
\hline Net worth (000's) & 0.117 & 0.14 & 233.84 \\
\hline Household income (000's) & 7.874 & 1.46 & 46.34 \\
\hline $\mathrm{R}$ or sp. retired ( 1 =yes) & 2188.516 & 1.42 & 0.37 \\
\hline No worker in hh ( 1 =yes) & -874.838 & -0.55 & 0.37 \\
\hline Two workers in hh (1=yes) & -4424.917 & $-2 \cdot 30$ & 0.21 \\
\hline Married or cohabiting ( 1 =yes) & 2604.098 & 0.28 & 0.60 \\
\hline Divorced or separated ( $1=y e s)$ & 7089.162 & 0.81 & 0.23 \\
\hline Widowed $(1=$ yes $)$ & 6572.977 & 0.75 & 0.14 \\
\hline Max life expectancy, age 70 & 50.008 & 3.97 & 79.39 \\
\hline $\mathrm{R}$ health excellent ( 1 =yes) & 6810.486 & 2.21 & 0.14 \\
\hline $\mathrm{R}$ health $\mathrm{V}$. good ( 1 =yes) & 4428.346 & 1.62 & 0.29 \\
\hline R health good ( 1 =yes) & 3346.511 & 1.31 & 0.30 \\
\hline $\mathrm{R}$ health fair $(1=$ yes $)$ & 1634.035 & 0.69 & 0.18 \\
\hline Sp. health excellent ( $1=y e s)$ & 6716.559 & 1.66 & 0.10 \\
\hline Sp. health v. good ( $1=$ yes) & 5362.520 & 1.45 & 0.20 \\
\hline Sp. health good ( 1 =yes) & 3946.214 & 1.11 & 0.18 \\
\hline Sp. health fair ( 1 =yes) & 4191.755 & 1.23 & 0.09 \\
\hline No. of low-income kids & -131.400 & -0.13 & 0.22 \\
\hline No. of middle-income kids & -35.094 & -0.06 & 0.69 \\
\hline No. of high-income kids & 950.229 & 1.76 & 1.29 \\
\hline No. of kids within 10 miles & 237.981 & 0.41 & 1.06 \\
\hline Year 1996 ( 1 =yes) & 1280.249 & 1.05 & 0.22 \\
\hline Year 1998 (1=yes) & -1666.220 & -1.24 & 0.18 \\
\hline Year 2000 ( 1 =yes) & -650.109 & -0.46 & 0.19 \\
\hline Year 2002 (1=yes) & -4349.046 & -2.85 & 0.18 \\
\hline Inherited this wave ( 1 =yes) & 10106.489 & 3.25 & 0.03 \\
\hline Inherited last wave ( 1 =yes) & 4754.054 & 1.47 & 0.03 \\
\hline Inherited 2 waves ago (1=yes) & 2657.482 & 0.73 & 0.02 \\
\hline Inherited 3 waves ago ( 1 =yes) & 3073.877 & 0.72 & 0.02 \\
\hline Inherited 4 waves ago ( 1 =yes) & 1785.079 & 0.37 & 0.01 \\
\hline Constant & 66326.620 & 7.34 & 1.00 \\
\hline Dependent variable mean & & 81,768 & \\
\hline $\mathrm{R}$-squared & & 0.009 & \\
\hline Number of respondents & & 3,217 & \\
\hline Number of observations & & 12,870 & \\
\hline
\end{tabular}

Source: Authors' calculations from Waves 2-6 of the HRS. 
Appendix Table 9. Intended bequests: Fixed effects estimates of net worth effects for strivers versus standard bearers

\begin{tabular}{|c|c|c|c|}
\hline & $\begin{array}{c}\text { Estimated } \\
\text { coefficient }\end{array}$ & $\begin{array}{l}\text { Estimated } \\
\text { t-value }\end{array}$ & $\begin{array}{c}\text { Variable } \\
\text { mean }\end{array}$ \\
\hline \multicolumn{4}{|l|}{ Explanatory variable } \\
\hline Household income (000's) & 15.481 & 1.60 & 47.70 \\
\hline $\mathrm{R}$ or $\mathrm{sp}$. retired ( 1 =yes) & 906.779 & 0.55 & 0.44 \\
\hline No worker in hh ( $1=$ yes) & 1005.966 & 0.58 & 0.38 \\
\hline Two workers in hh (1=yes) & -2253.629 & -1.09 & 0.22 \\
\hline Married or cohabiting ( 1 =yes) & 5490.701 & 0.50 & 0.64 \\
\hline Divorced or separated ( $1=y e s)$ & -2510.692 & -0.24 & 0.20 \\
\hline Widowed $(1=$ yes $)$ & -2401.975 & -0.23 & 0.14 \\
\hline Max life expectancy, age 70 & 40.110 & 2.97 & 79.05 \\
\hline $\mathrm{R}$ health excellent ( 1 =yes) & 6842.693 & 1.98 & 0.14 \\
\hline $\mathrm{R}$ health $\mathrm{v}$. good ( $1=$ yes) & 4721.656 & 1.52 & 0.32 \\
\hline R health good ( 1 =yes) & 1312.161 & 0.45 & 0.30 \\
\hline $\mathrm{R}$ health fair ( 1 =yes $)$ & -514.657 & -0.19 & 0.17 \\
\hline Sp. health excellent ( 1 =yes) & -7154.052 & -1.61 & 0.11 \\
\hline Sp. health v. good ( $1=$ yes) & -4693.130 & -1.15 & 0.23 \\
\hline Sp. health good ( $1=$ yes) & -6424.782 & -1.65 & 0.19 \\
\hline Sp. health fair ( $1=$ yes) & -2262.502 & -0.60 & 0.09 \\
\hline No. of low-income kids & -1349.922 & -0.96 & 0.18 \\
\hline No. of middle-income kids & 425.347 & 0.60 & 0.67 \\
\hline No. of high-income kids & 726.672 & 1.14 & 1.38 \\
\hline No. of kids within 10 miles & 144.553 & 0.22 & 0.99 \\
\hline Year 1998 ( 1 =yes $)$ & -1068.710 & -0.86 & 0.25 \\
\hline Year 2000 ( $1=$ yes $)$ & -107.900 & -0.08 & 0.25 \\
\hline Year 2002 ( 1 =yes $)$ & -4183.638 & -2.94 & 0.25 \\
\hline Inherited this wave ( 1 =yes) & 13614.295 & 3.80 & 0.02 \\
\hline Inherited last wave ( $1=$ yes) & 8106.572 & 2.22 & 0.02 \\
\hline Inherited 2 waves ago ( 1 =yes) & 7242.330 & 2.23 & 0.04 \\
\hline Inherited 3 waves ago ( 1 =yes) & 6737.599 & 1.90 & 0.03 \\
\hline Inherited 4 waves ago ( 1 =yes) & 4521.227 & 1.19 & 0.02 \\
\hline Net worth times striver & 20.515 & 1.63 & 11.31 \\
\hline Net worth times std. bearer & -0.043 & -0.01 & 99.76 \\
\hline Net worth times traditionless & 10.727 & 2.66 & 135.45 \\
\hline Constant & 82138.845 & 7.58 & 1.00 \\
\hline Dependent variable mean & & 91,171 & \\
\hline R-squared & & 0.013 & \\
\hline Number of respondents & & 2,771 & \\
\hline Number of observations & & 9,801 & \\
\hline
\end{tabular}

Source: Authors' calculations from Waves 2-6 of the HRS. 


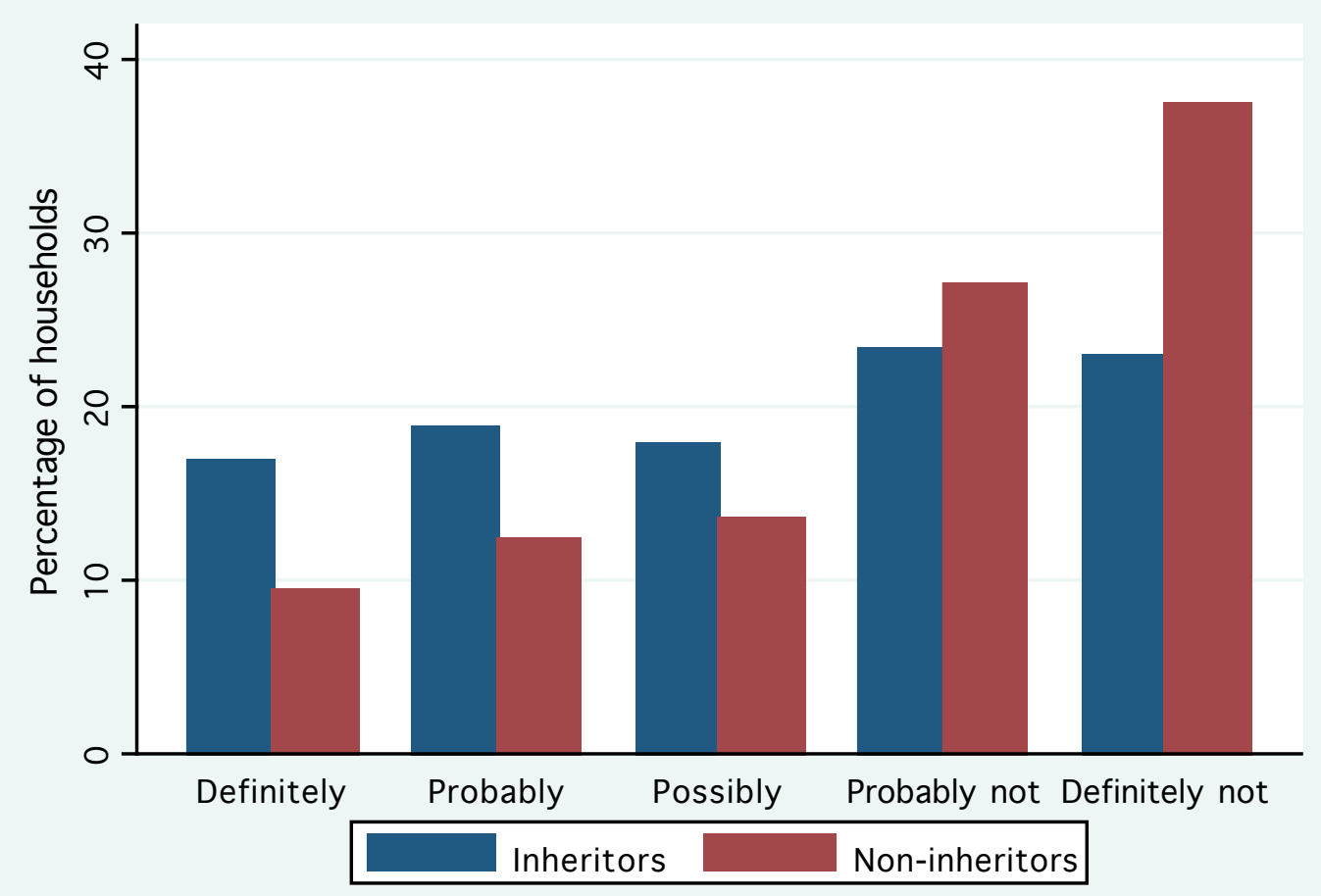

Source: Authors' calculations from Wave 1 of the HRS.

Figure 5. Expectations of leaving a sizeable bequest: inheritors versus non-inheritors

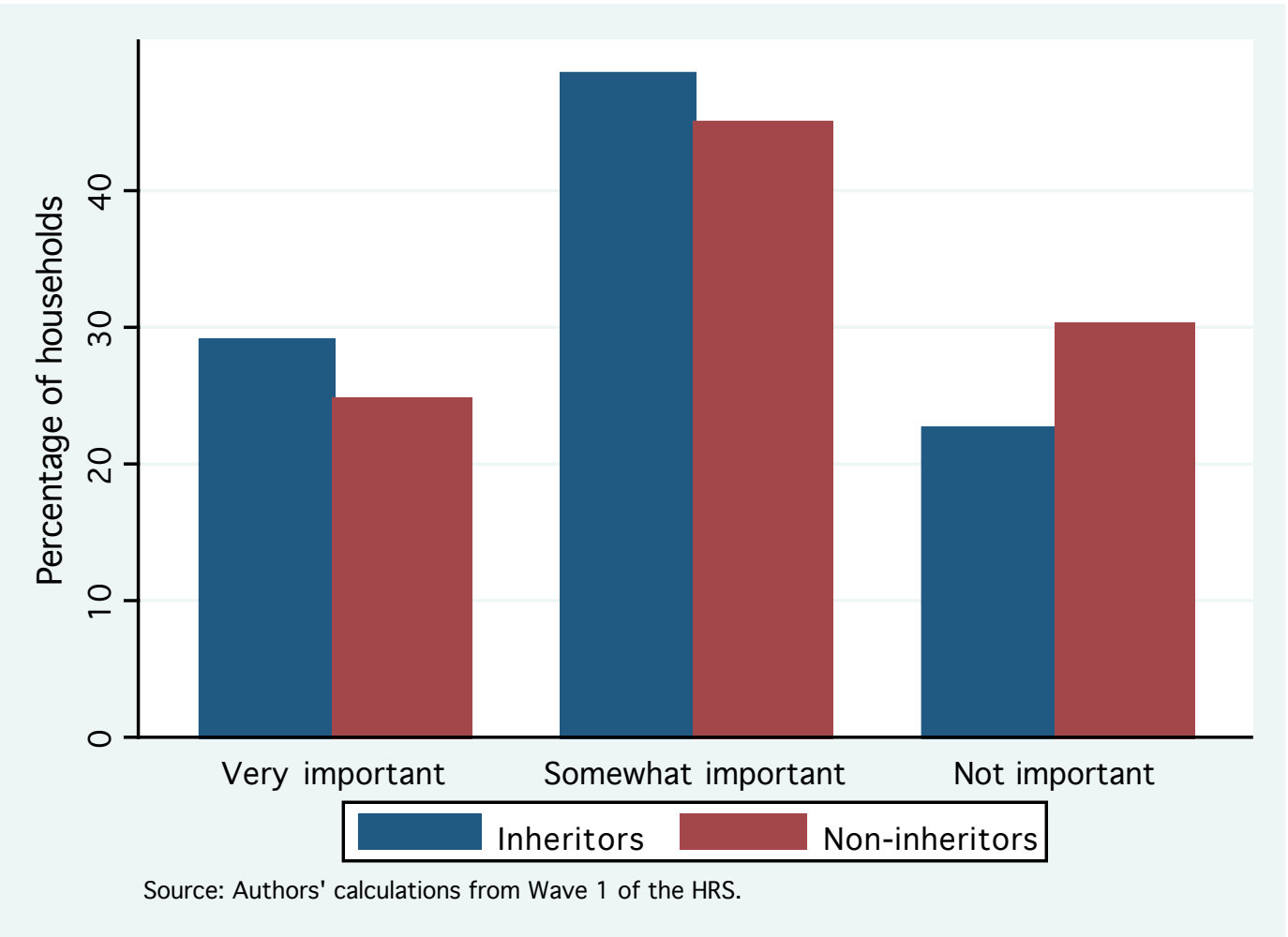

Figure 6. The importance of leaving a bequest: inheritors versus non-inheritors 


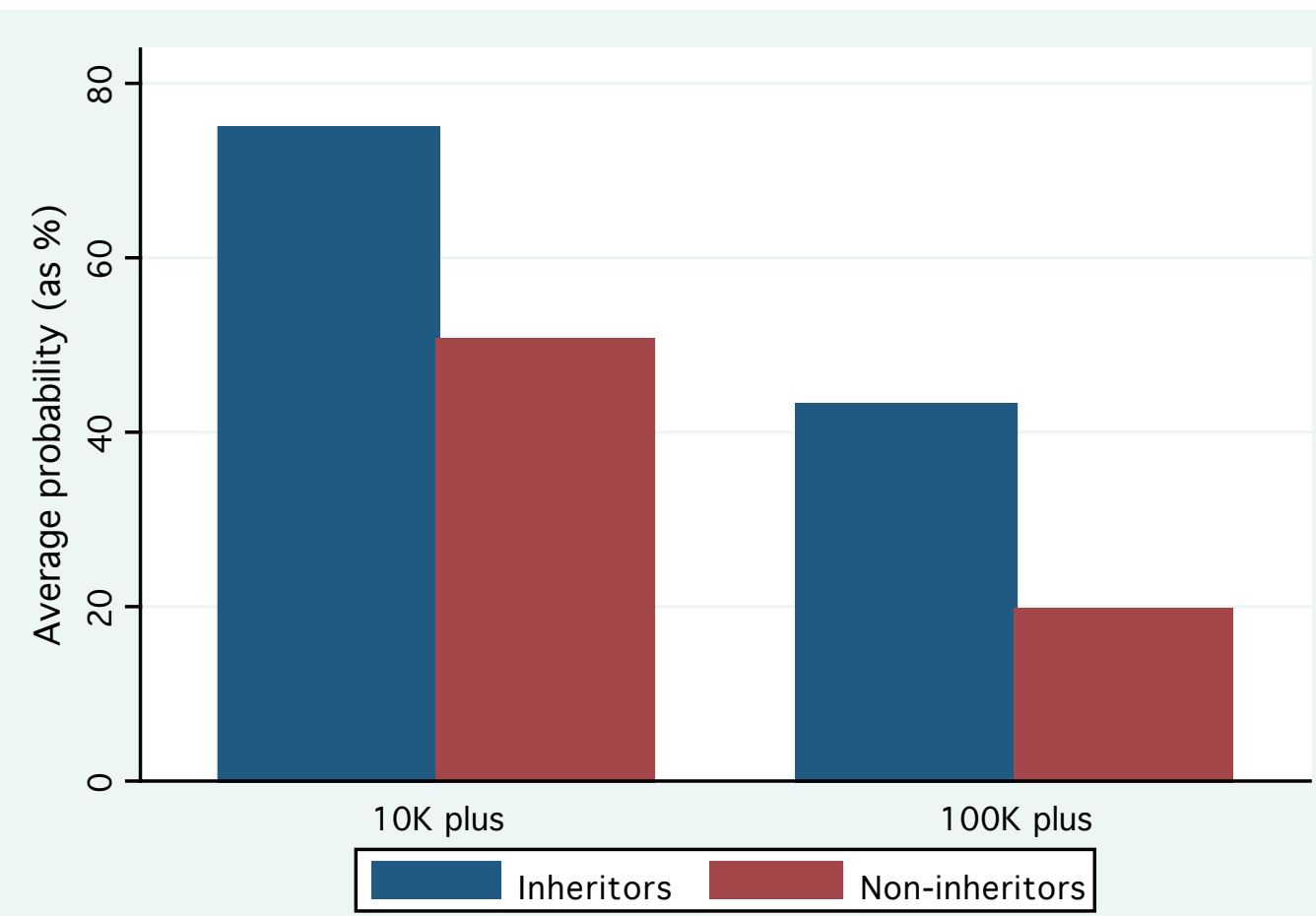

Source: Authors' calculations from Wave 2 of the HRS.

Figure 7. The chances of leaving a bequest: inheritors versus non-inheritors

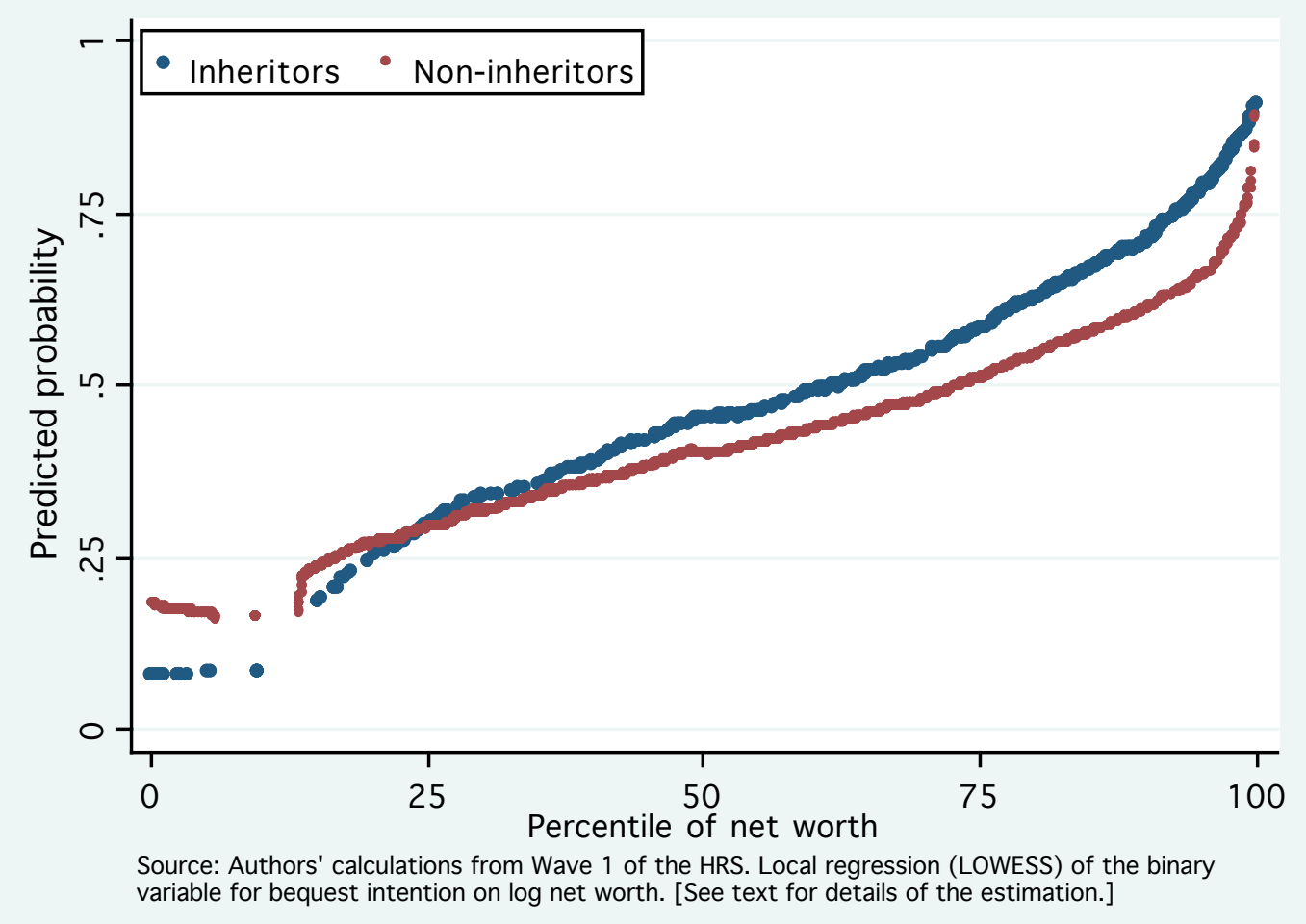

Figure 8. Intentions to bequeath and net worth: inheritors versus non-inheritors 


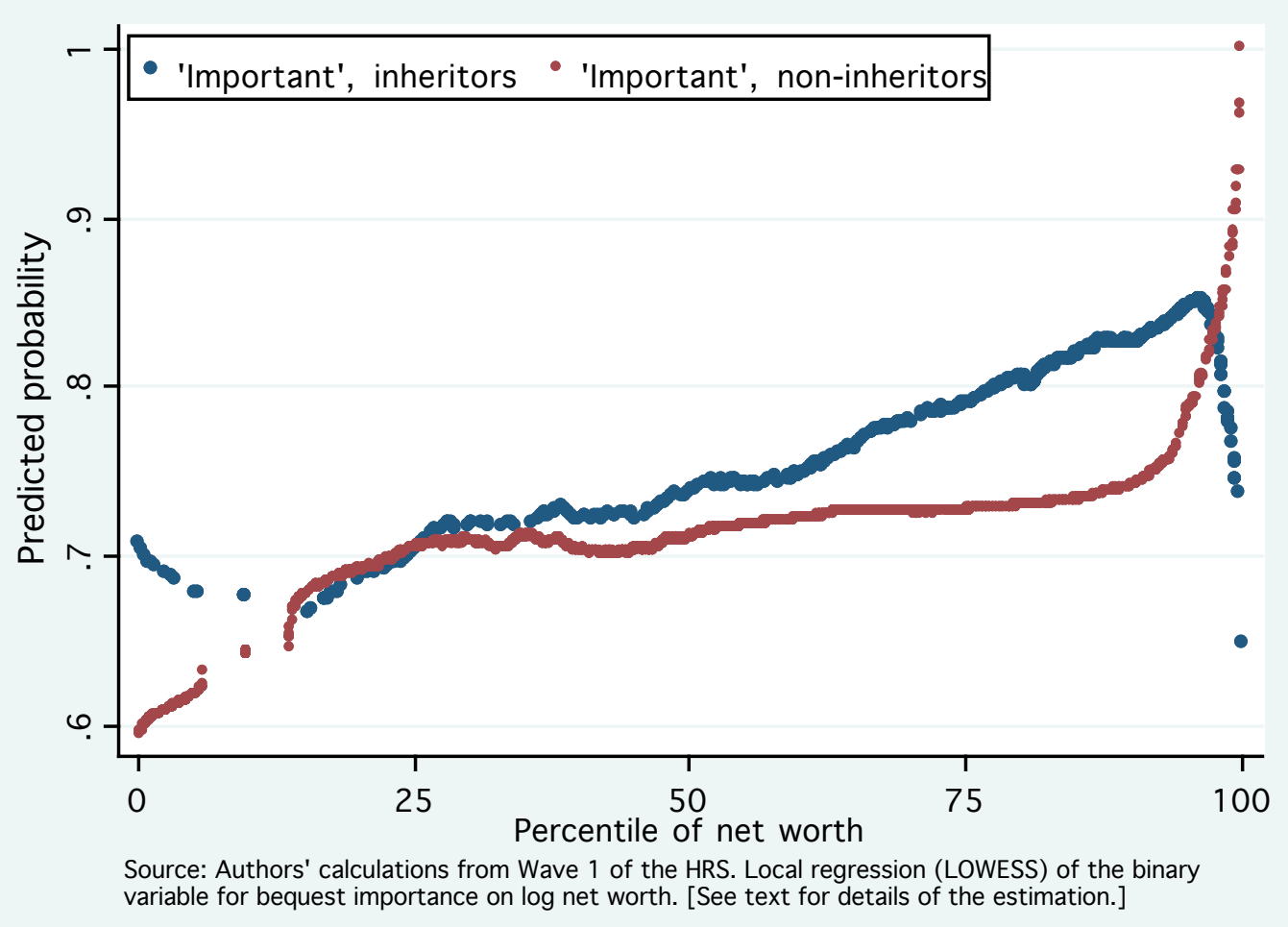

Figure 9. The importance of bequeathing and net worth: inheritors versus noninheritors

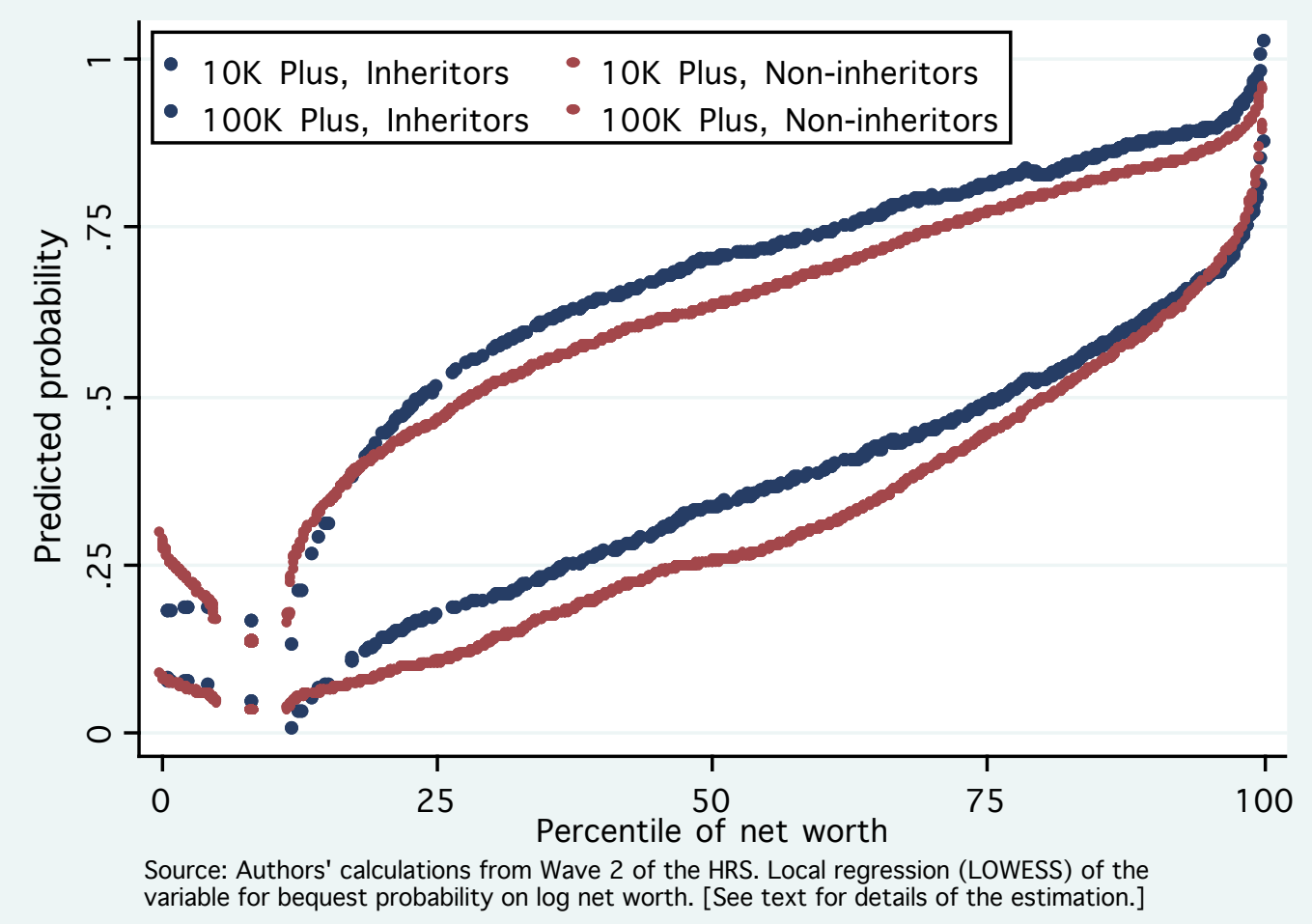

Figure 10. The probability of leaving a bequest and net worth: inheritors versus noninheritors 


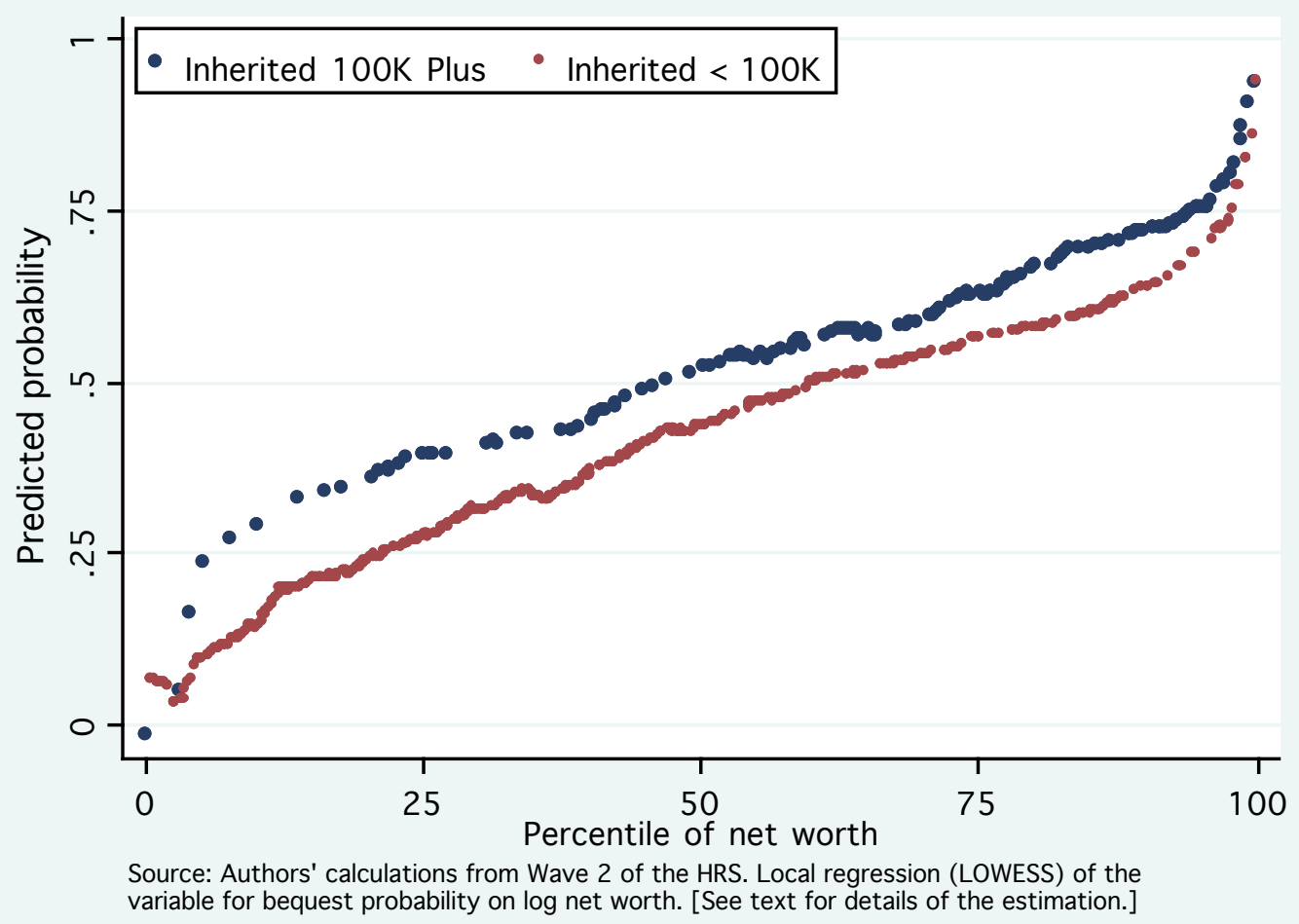

Figure 11. The probability of leaving a bequest valued $\$ 100,000$ or more and net worth: " $100 \mathrm{~K}+$ " inheritors versus " $100 \mathrm{~K}-$ - inheritors

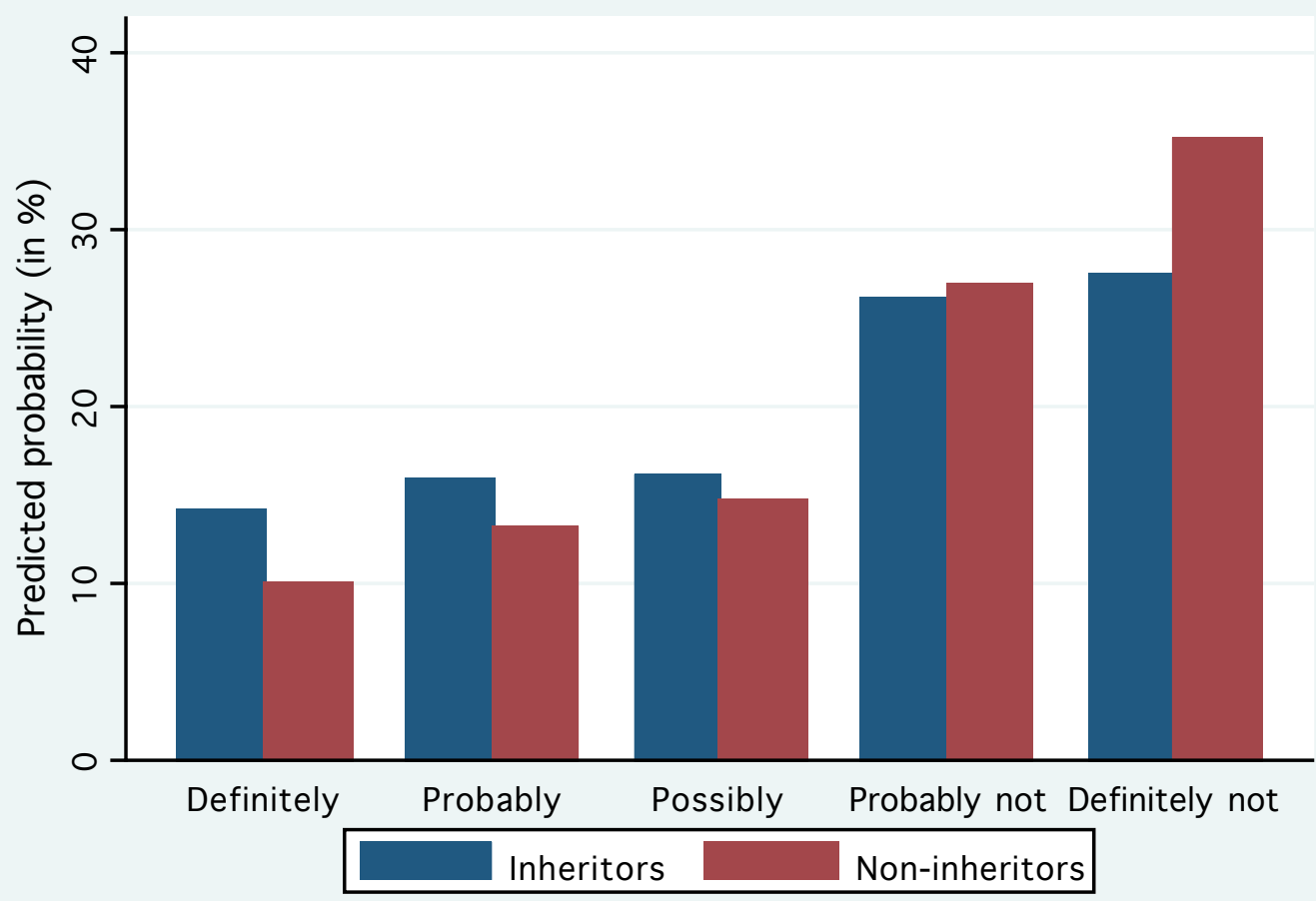

Source: Regression results from Appendix Table 2, using Wave 1 of the HRS.

Figure 12. The predicted expectation of leaving a sizeable bequest: inheritors versus non-inheritors 


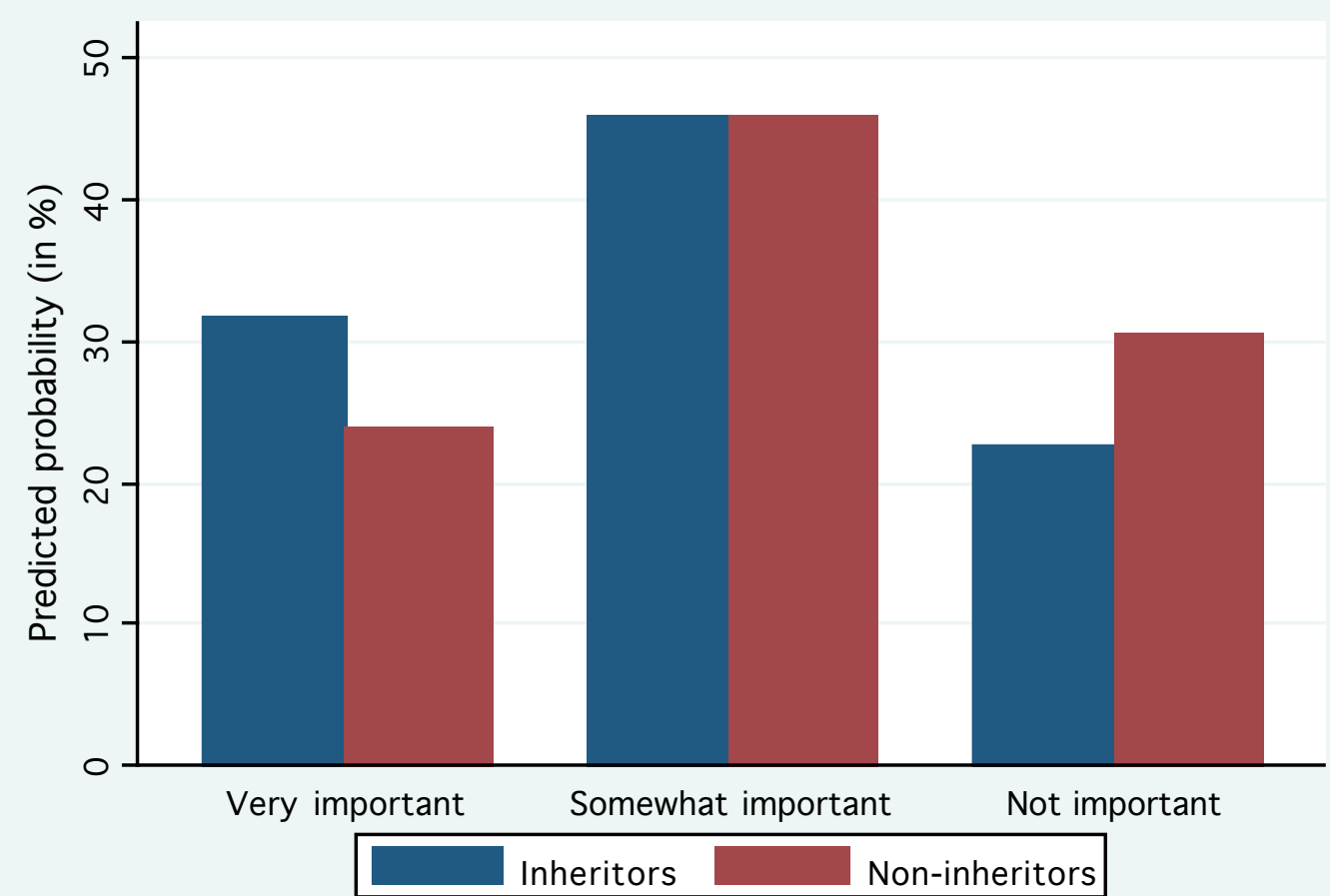

Source: Regression results from Appendix Table 3, using Wave 1 of the HRS.

Figure 13. The predicted importance of leaving a bequest: inheritors versus noninheritors

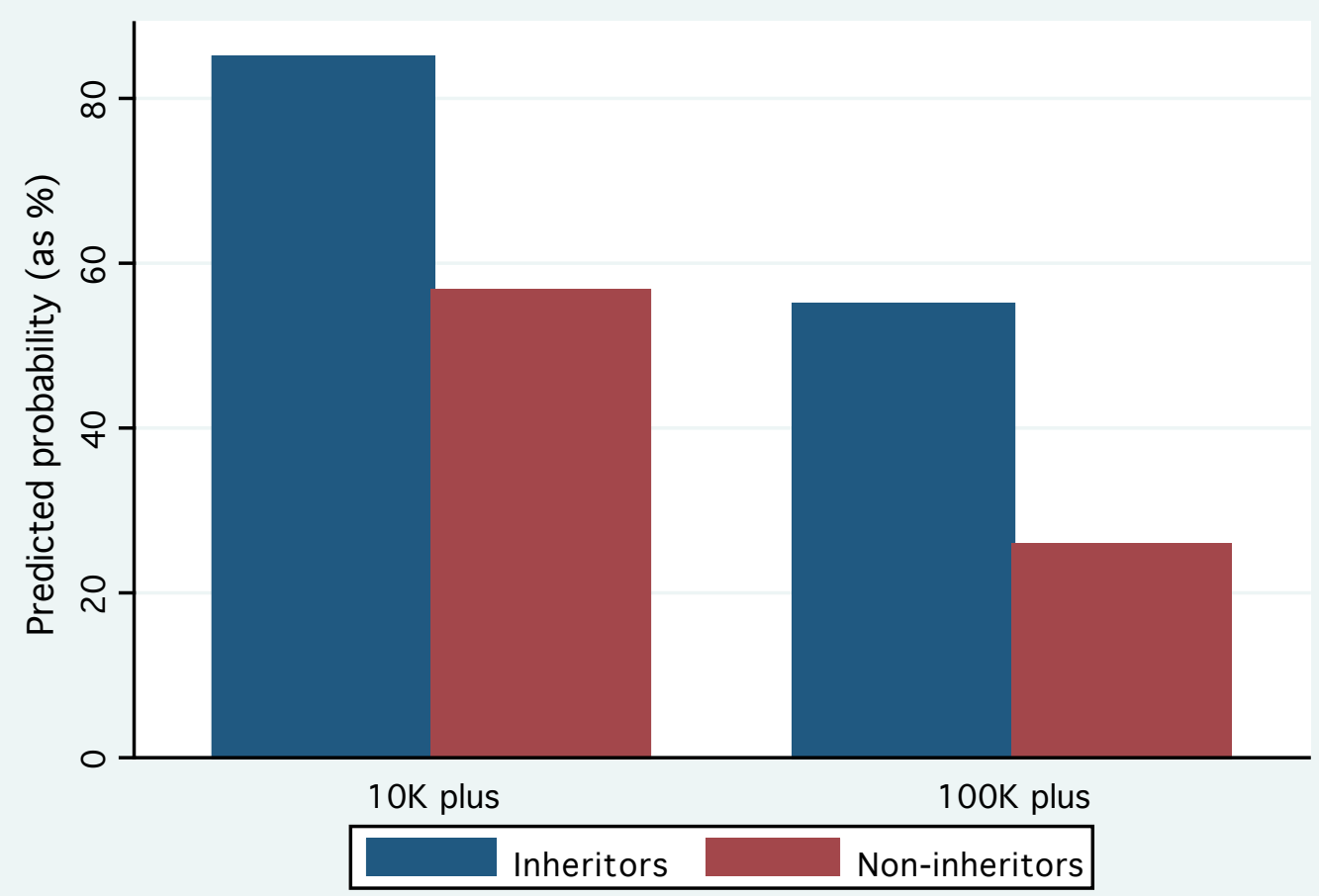

Source: Regression results from Appendix Tables 4 and 5, using Wave 2 of the HRS.

Figure 14. The predicted chances of leaving a bequest: inheritors versus noninheritors 


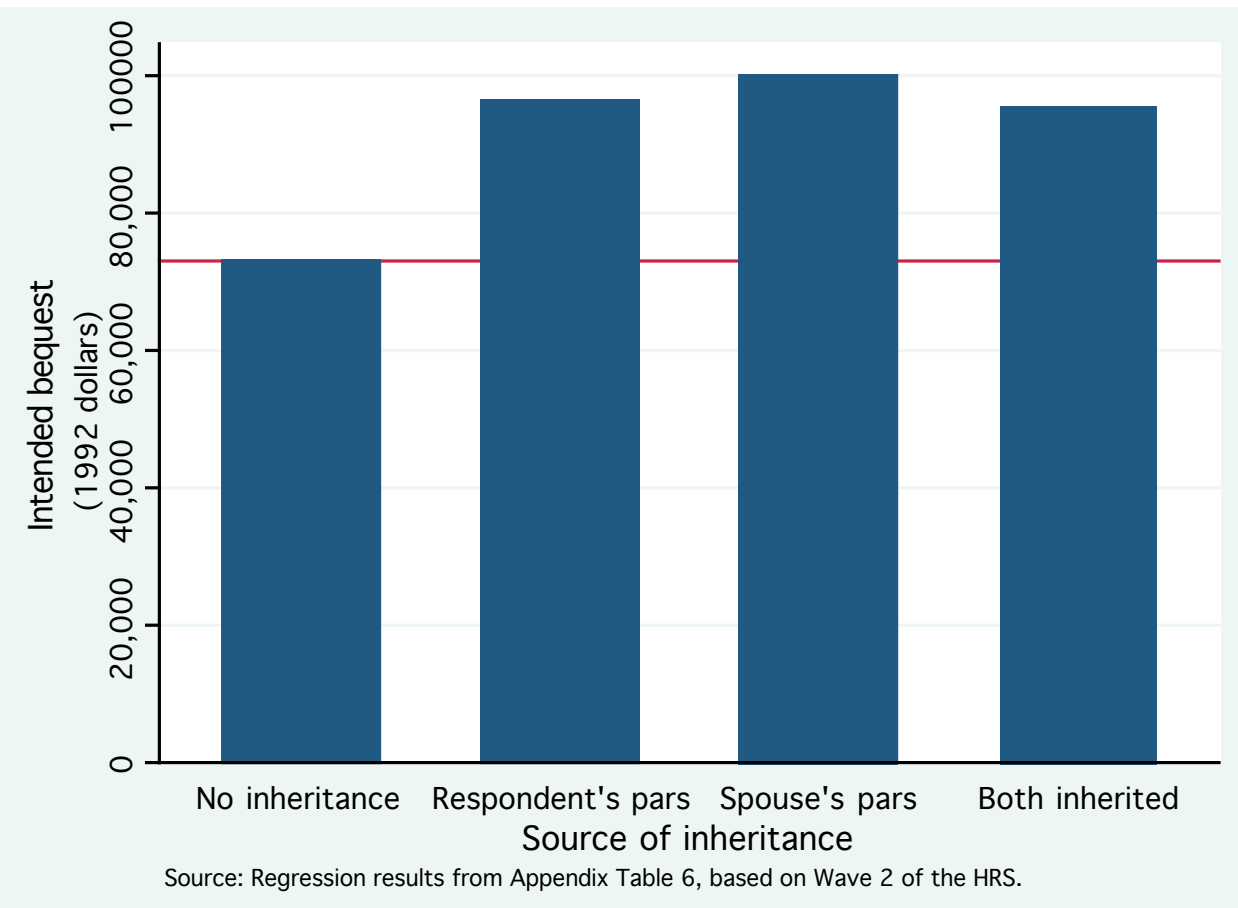

Figure 15. The dollar impact of inheritance on intended household bequests

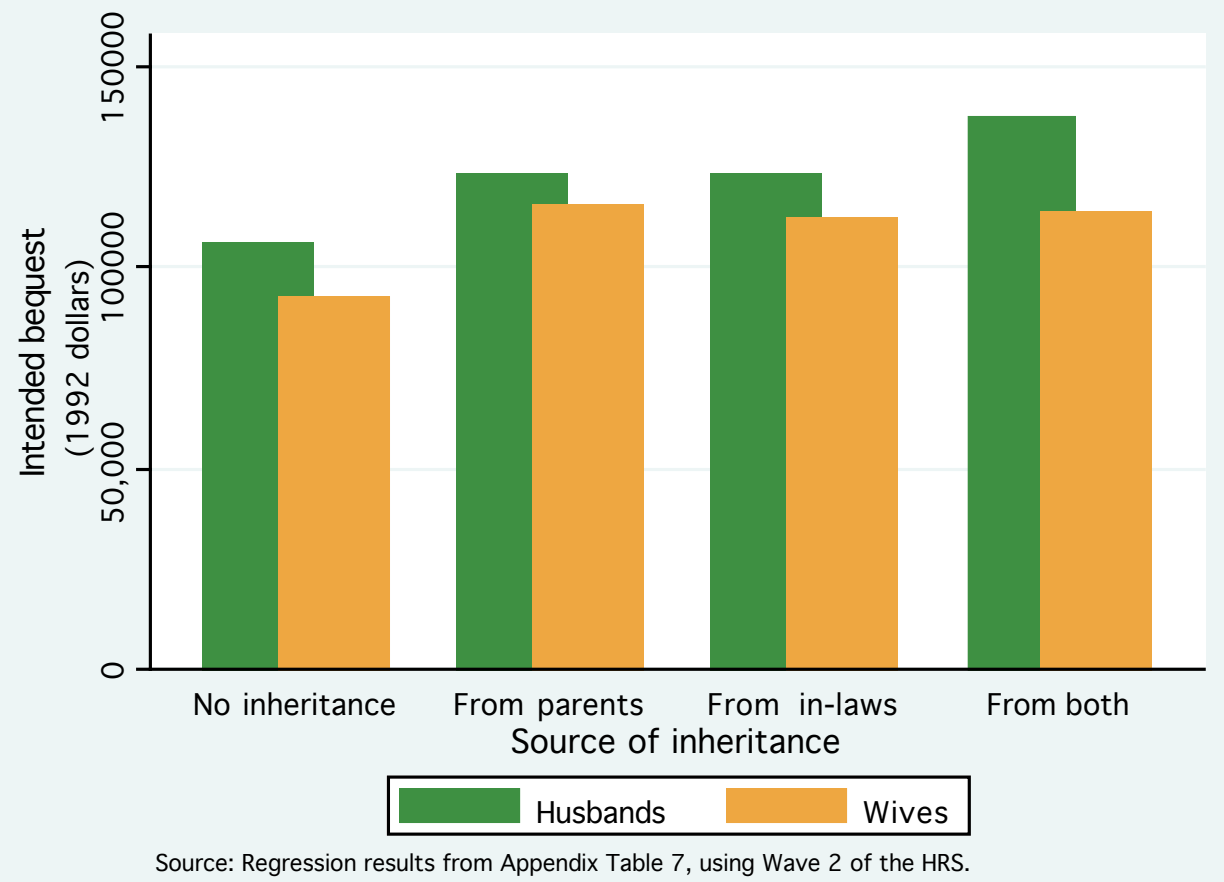

Figure 16. Source of inheritance and intended bequests: husbands and wives separately, by inheritance status 


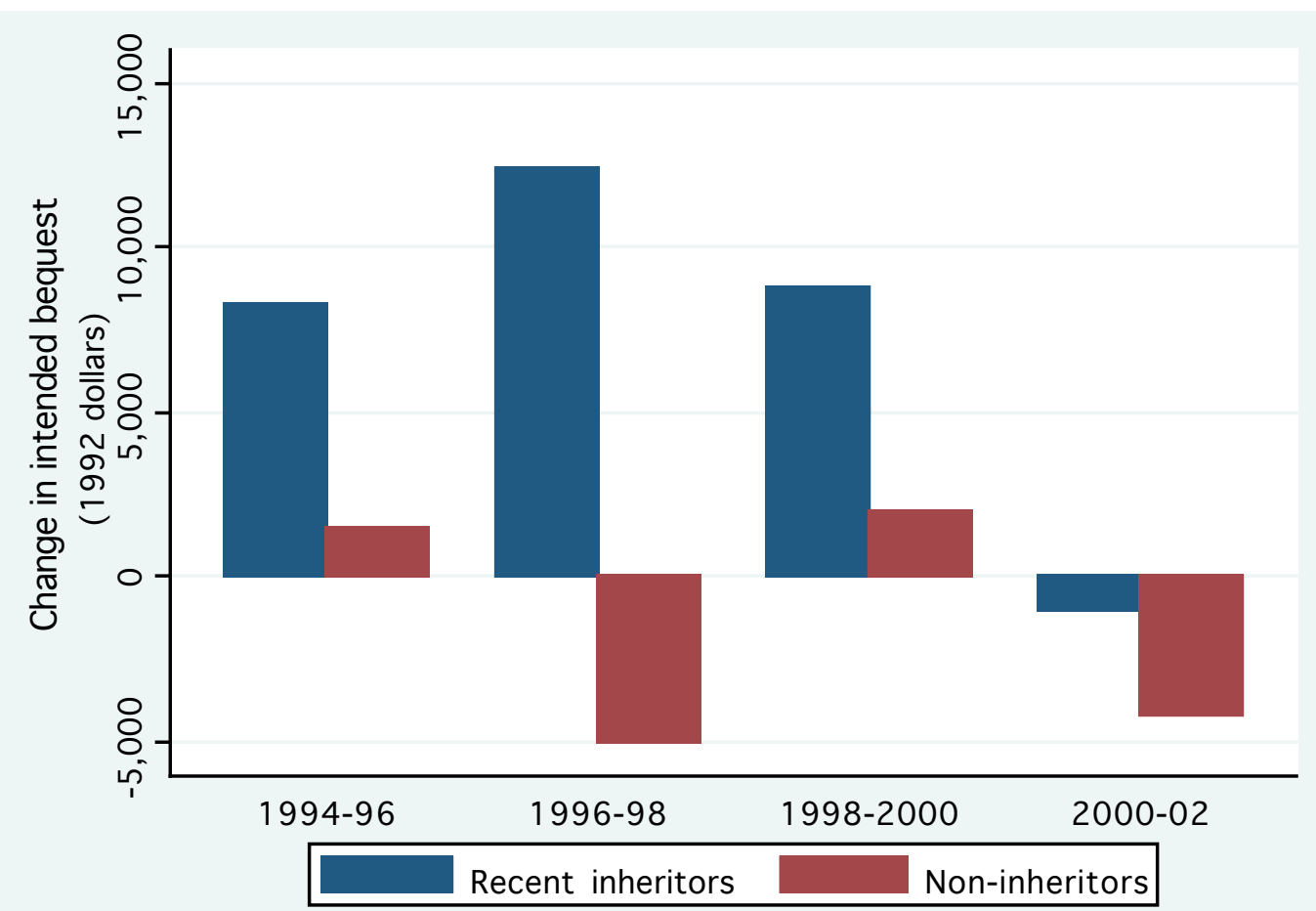

Source: Authors' calculations from Wave 2-6 of the HRS.

Figure 17. Change in intended bequests between waves: those who inherited between waves versus those who did not

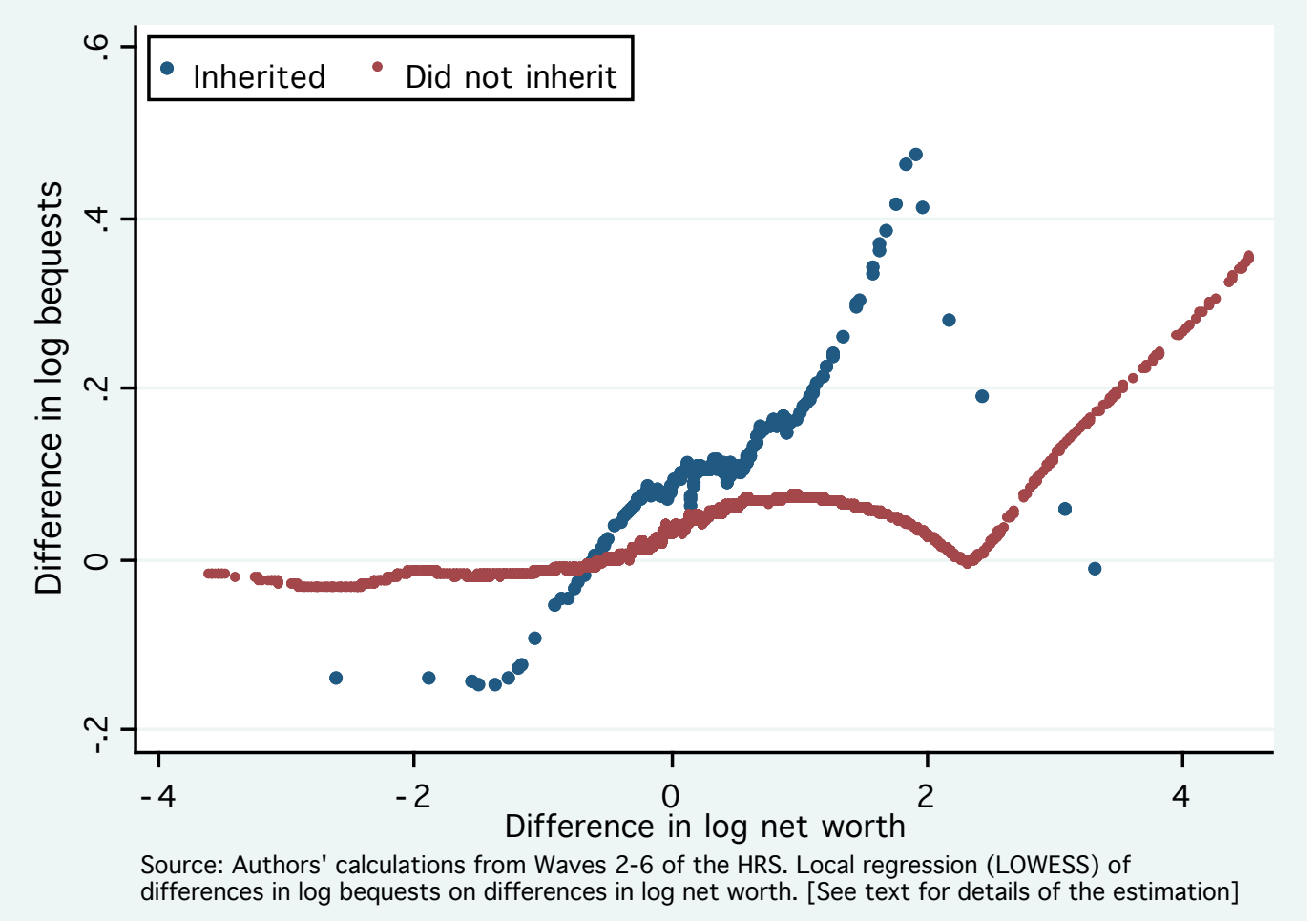

Figure 18. Changes in bequests and in net worth: respondents who inherited between waves versus respondents who did not 


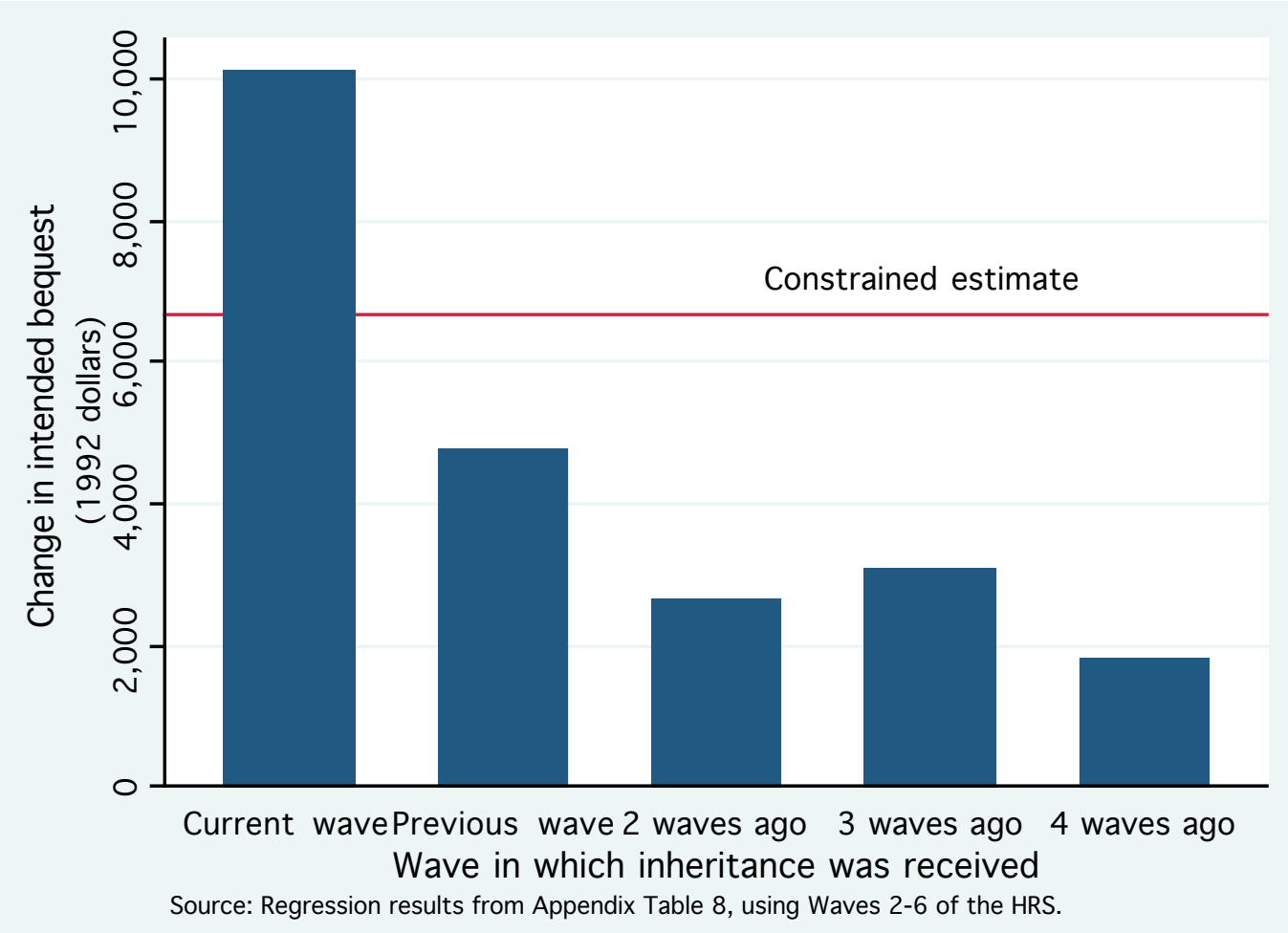

Figure 19. Effects of inheritance on intended bequests

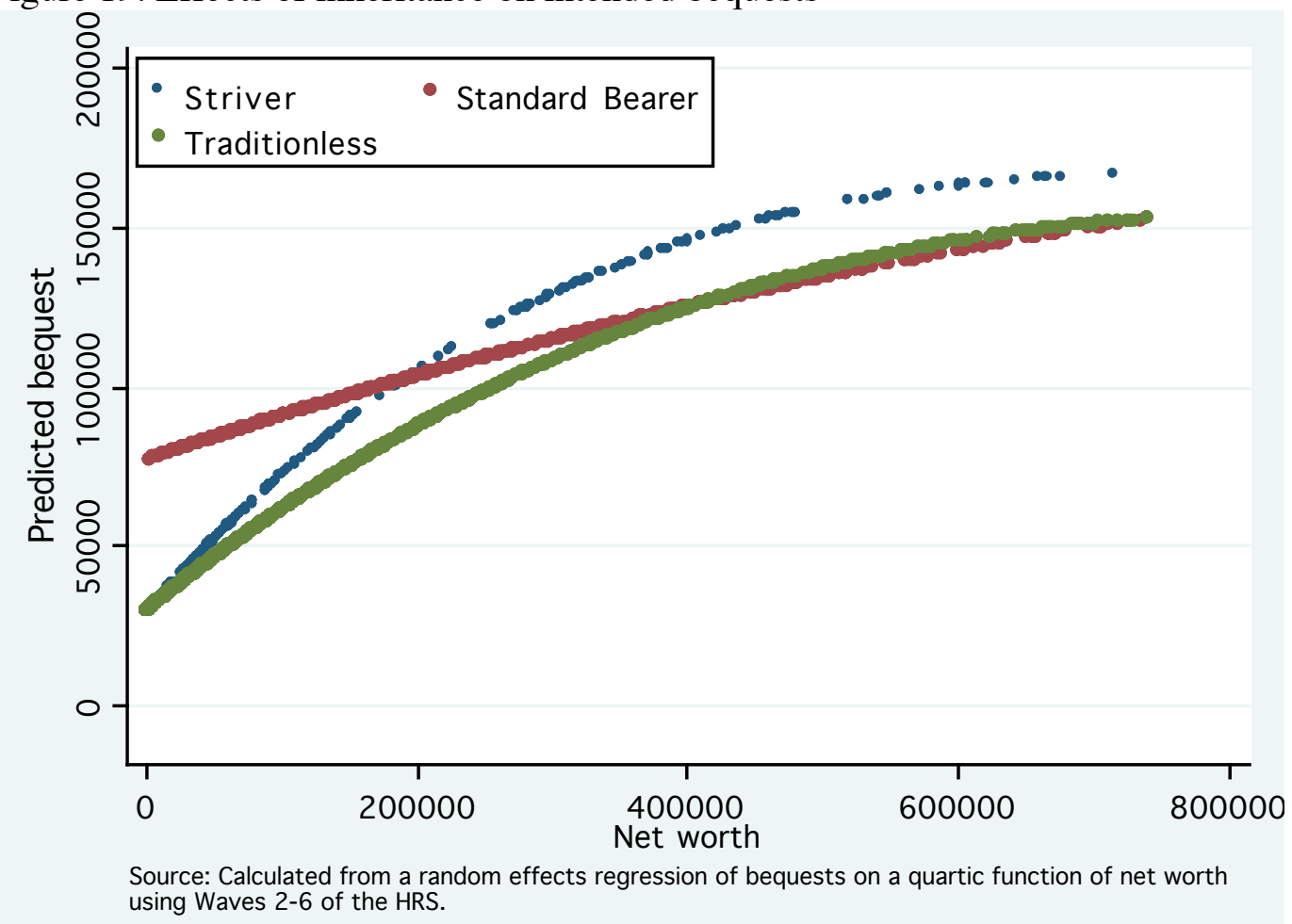

Figure 20. Intended bequests and net worth: respondents whose net worth exceeds their inheritance versus respondents whose net worth does not; non-inheritors included as well 


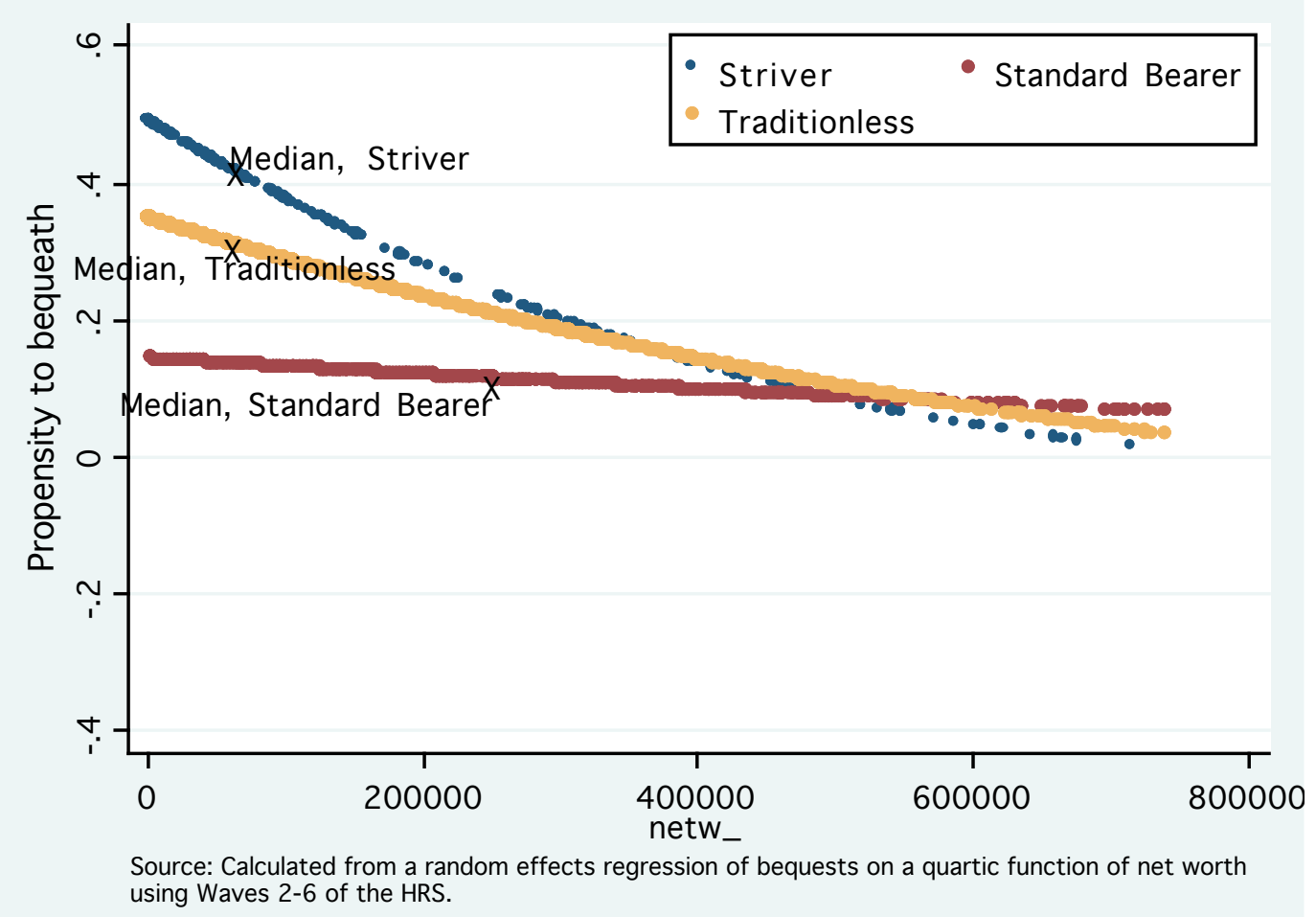

Figure 21. Propensity to bequeath out of net worth: strivers, standard bearers and no tradition

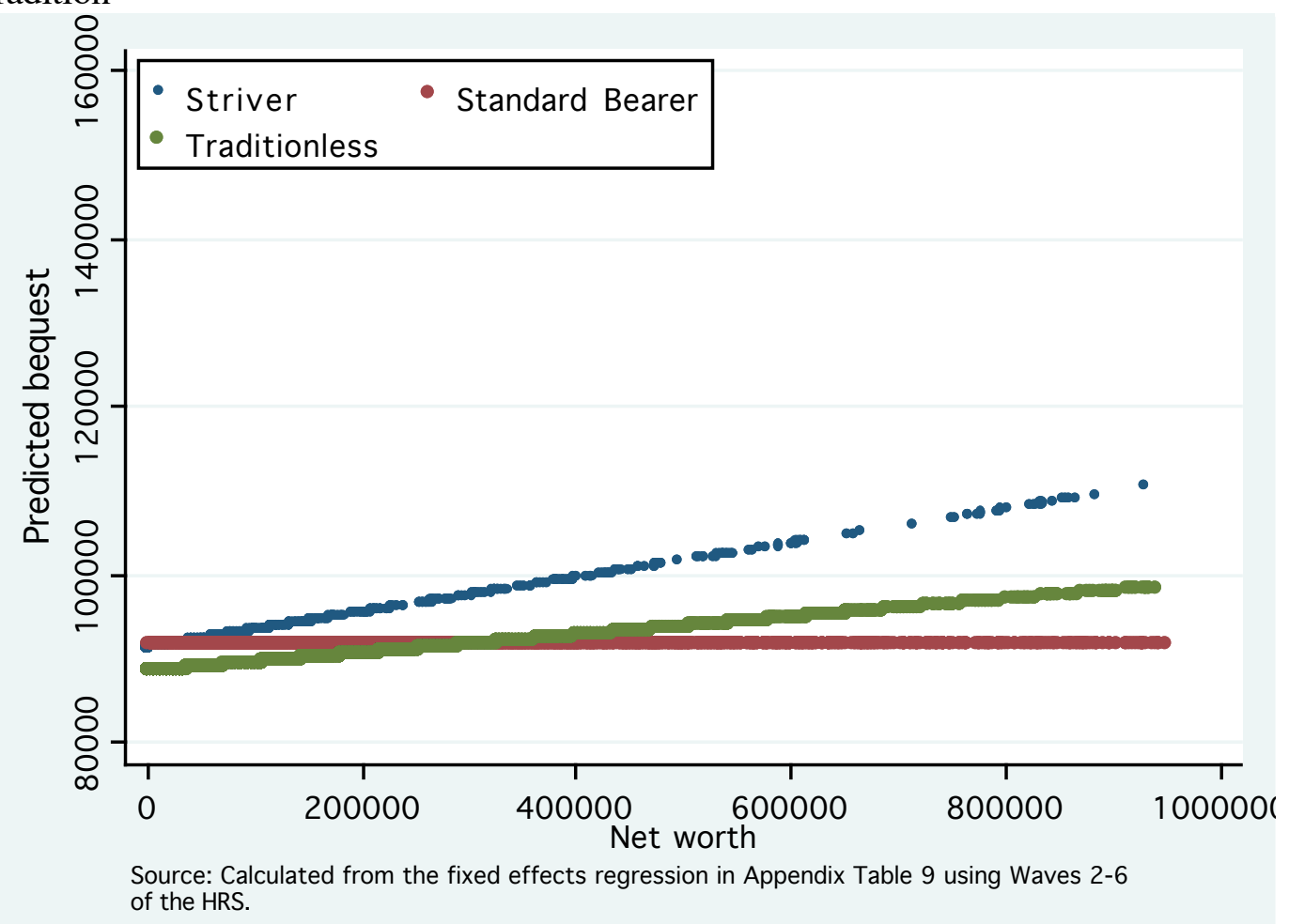

Figure 22. Intended bequests and net worth: strivers, standard bearers and no tradition 


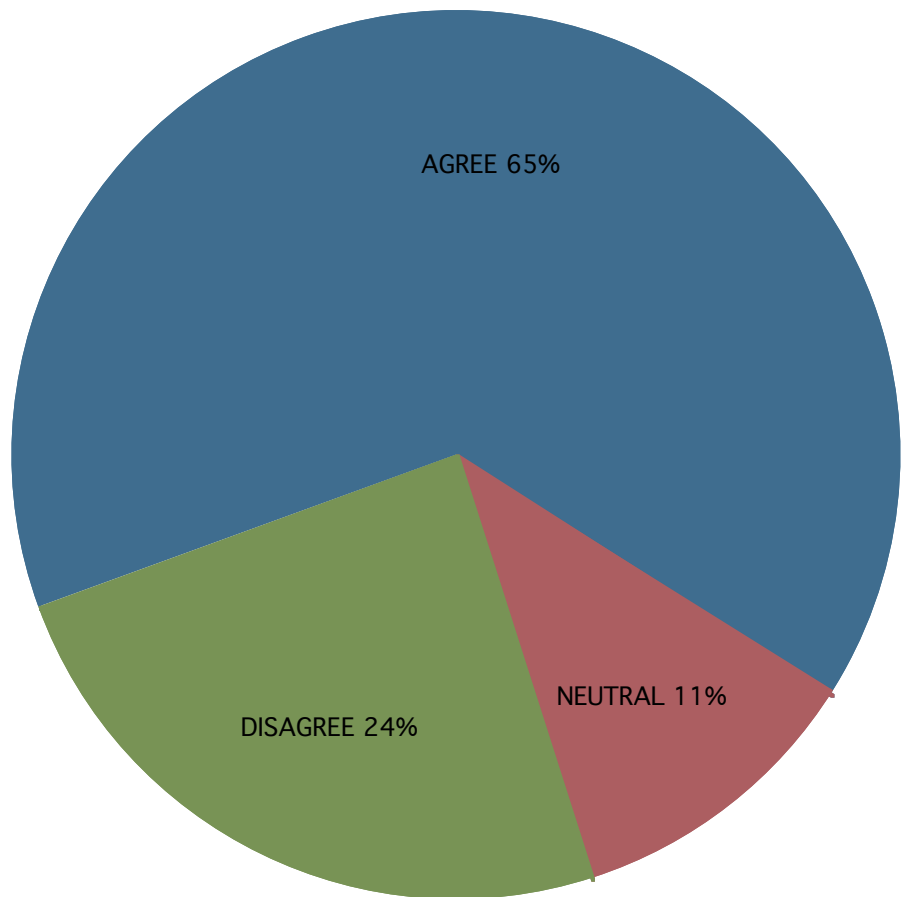

Source: Authors' calculations from Benevolence and Obligation Module, Wave 5 of the HRS.

Figure 23. Responses to the "point blank" statement:

"I do for my children what my parents did for me" 


\section{RECENT WORKING PAPERS FROM THE \\ CENTER FOR RETIREMENT RESEARCH AT BOSTON COLLEGE}

Local Labor Market Conditions and Retirement Behavior

Dan A. Black and Xiaoli Liang, May 2005

Validation Study of Earnings Data in the SIPP_Do Older Workers Have Larger Measurement Error?

Peter Gottschalk and Minh Huynh, May 2005

Investment Choice in the Swedish Premium Pension Plan

Mårten Palme, Annika Sundén, and Paul Söderlind, April 2005

Design and Implementation Issues in Swedish Individual Pension Accounts

R. Kent Weaver, April 2005

Lashed to the Mast?: The Politics of Notional Defined Contribution Pension Reforms

Sarah M. Brooks and R. Kent Weaver, January 2005

Understanding Expenditure Patterns in Retirement

Barbara A. Butrica, Joshua H. Goldwyn, and Richard W. Johnson, January 2005

Changes in the Distribution of Long-Run Earnings and Retirement Incomes-Have Recent Cohorts Fallen Behind?

Peter Gottschalk and Minh Huynh, January 2005

The Age Profile of Income and the Burden of Unfunded Transfers in Four

Countries: Evidence from the Luxembourg Income Study

Gary Burtless, December 2004

Projecting Immigration: A Survey of the Current State of Practice and Theory Neil Howe and Richard Jackson, December 2004

Nonearnings Income Migration in the United States: Anticipating the Geographical Impacts of Baby Boom Retirement

Peter B. Nelson, December 2004

All working papers are available on the Center for Retirement Research website (http://www.bc.edu/crr) and can be requested by e-mail (crr@bc.edu) or phone (617-552-1762). 